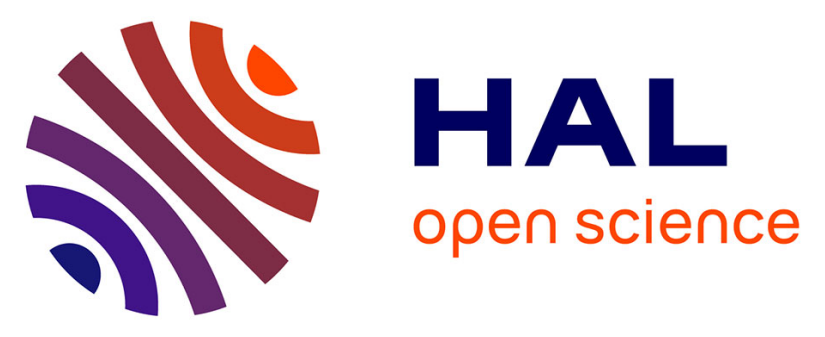

\title{
Tellurium and selenium sorption kinetics and solid fractionation under contrasting estuarine salinity and turbidity conditions
}

Teba Gil-Díaz, Jörg Schäfer, Virginia Keller, Elisabeth Eiche, Lionel Dutruch, Claudia Mössner, Markus Lenz, Frédérique Eyrolle

\section{To cite this version:}

Teba Gil-Díaz, Jörg Schäfer, Virginia Keller, Elisabeth Eiche, Lionel Dutruch, et al.. Tellurium and selenium sorption kinetics and solid fractionation under contrasting estuarine salinity and turbidity conditions. Chemical Geology, 2020, 532, pp.119370 -. 10.1016/j.chemgeo.2019.119370 . hal-03488405

\author{
HAL Id: hal-03488405 \\ https://hal.science/hal-03488405
}

Submitted on 21 Dec 2021

HAL is a multi-disciplinary open access archive for the deposit and dissemination of scientific research documents, whether they are published or not. The documents may come from teaching and research institutions in France or abroad, or from public or private research centers.
L'archive ouverte pluridisciplinaire HAL, est destinée au dépôt et à la diffusion de documents scientifiques de niveau recherche, publiés ou non, émanant des établissements d'enseignement et de recherche français ou étrangers, des laboratoires publics ou privés.

\section{(ㅇ)(1) $\$$}

Distributed under a Creative Commons Attribution - NonCommerciall 4.0 International 


\title{
Tellurium and selenium sorption kinetics and solid fractionation under contrasting estuarine salinity and turbidity conditions
}

\author{
Teba Gil-Díaz ${ }^{\mathrm{a}}$, Jörg Schäfer ${ }^{\mathrm{a} *}$, Virginia Keller ${ }^{\mathrm{b}}$, Elisabeth Eiche ${ }^{\mathrm{b}}$, Lionel Dutruch ${ }^{\mathrm{a}}$, Claudia Mößner ${ }^{\mathrm{b}}$,
}

Markus Lenz ${ }^{\mathrm{c}}$, Frédérique Eyrolle ${ }^{\mathrm{d}}$

${ }^{a}$ Université de Bordeaux, UMR CNRS 5805 EPOC, NB18, Allée Geoffroy Saint-Hilaire, 33615 Pessac, France; ${ }^{b}$ Institute of Applied Geosciences, Karlsruhe Institute of Technology (KIT), Adenauerring 20b, 76131 Karlsruhe, Germany; 'Institute for Ecopreneurship, University of Applied Sciences and Arts Northwestern Switzerland (FHNW), School of Life Sciences, Gründenstrasse 40, 4132 Muttenz, Switzerland; 'Institut de Radioprotection et de Sûreté Nucléaire (IRSN), PSE-ENV/SRTE/LRTA,BP 3, 13115, Saint Paul Lez Durance, France

*corresponding author: jorg.schafer@u-bordeaux.fr

\section{Abstract}

Tellurium (Te) is a Technology Critical Element (TCE) and a relevant product of nuclear fission. It has an unknown environmental biogeochemical cycle, mostly related to current analytical challenges in measuring its ultra-trace dissolved concentrations in complex environmental matrices. It is therefore generally compared to its geochemical pair selenium (Se), which shows a narrow range between diet essentiality and toxicity properties. Batch experiments using isotopically-labelled stable $\mathrm{Te}$ and $\mathrm{Se}$ were performed with fresh suspended particulate matter (SPM) from the fluvial part of the Gironde Estuary, simulating both estuarine salinity ( $\mathrm{S}=0$ vs $\mathrm{S}=32$ ) and turbidity $\left(100 \mathrm{mg} \mathrm{L}^{-1}\right.$ vs $1000 \mathrm{mg} \mathrm{L}^{-1}$ ) gradients to understand the importance of the particulate phases in Te reactivity under estuarine conditions and verify the resemblance to Se behaviour. These experiments addressed sorption kinetics, sorption isotherms and fractionation from selective extractions of final equilibrated SPM. Results showed a strong, salinity-independent affinity of Te for the particulate phases $\left(\log _{10} \mathrm{Kd} \sim 4.9 \mathrm{~L} \mathrm{~kg}^{-1}\right)$, following a Langmuir-type isotherm. Contrastingly, Se adsorbs clearly less to estuarine SPM $\left(\log _{10} \mathrm{Kd}\right.$ $\sim 2.5 \mathrm{~L} \mathrm{~kg}^{-1}$ ), following a Freundlich-type isotherm. Both isotherms and selective extractions highlighted differences between $\mathrm{Te}$ and Se sequestration. Selective extractions suggested higher mobility of particulate Se in contrast to Te. Based on these results the paper sets a first dispersion scenario on the environmental fate of radioactive Te and Se after hypothetical nuclear power plant accidental releases in coastal aquatic systems such as the Garonne-Gironde fluvial-estuarine system.

Keywords: technology critical elements, isotherms, selective extractions, distribution coefficient $(\mathrm{Kd})$, Te environmental cycle, radionuclide releases 
Radioactive tellurium (Te) is produced during nuclear fission reactions in non-negligible quantities. All Te radionuclides have a 13-16\% probability of being produced from ${ }^{239} \mathrm{Pu}$ - and ${ }^{235} \mathrm{U}$-based fuels compared to $\sim 11 \%$ for Cs and $\sim 10 \%$ for I radionuclides (unpublished data calculated from Element Collection Inc. and Sonzogni 2013). There is little information on the specific Te species released from nuclear power plant (NPP) accidents, potentially presenting both (i) volatile/intermediate (Morewitz 1981), and (ii) refractory character (e.g., forming metal/oxide compounds; Kleykamp 1985; Izrael 2002 and references therein). Though different NPP accidents display different emission patterns, Te radionuclides were released into the environment during both April-1986 Chernobyl (CNPP) and March-2011 Fukushima Daiichi (FDNPP) accidental events (Steinhauser et al. 2014). In these cases, short-term half-life Te radionuclides (e.g., ${ }^{132} \mathrm{Te}$ half-life of 3.2 days) produced important atmospheric radioactive emissions ( ${ }^{132} \mathrm{Te}: \sim 1150 \mathrm{PBq}$ at CNPP and $\sim 180 \mathrm{PBq}$ at FDNPP) comparable to ${ }^{137} \mathrm{Cs}$ and ${ }^{131} \mathrm{I}$, the most monitored radionuclides after NPP accidental events ( $\sim 85 \mathrm{PBq}$ and $\sim 1700$ PBq at CNPP, $\sim 37$ PBq and $\sim 160$ PBq at FDNPP, respectively; Steinhauser et al. 2014). Emitted Te radionuclides were still detected in the atmosphere one month after the FDNPP accident reflecting their non-negligible environmental persistence and potential worldwide atmospheric dispersion (Baeza et al. 2012; Ishikawa et al. 2014; Leppänen et al. 2013). In fact, radioactive Te has been detected in FDNPP fallouts (Saegusa et al. 2013) and in seawater from Monaco, after CNPP (May 1986), yet with relatively low ${ }^{129} \mathrm{Te}$ activities in the dissolved $\left(0.13 \mathrm{~Bq} \mathrm{~L}^{-1}\right)$ and particulate $\left(1.18 \mathrm{mBq} \mathrm{L}^{-1}\right)$ phases (Whitehead et al. 1988). The latter study further suggested for the first time the moderate particlereactive behaviour of radioactive $\mathrm{Te}$ and its potential intake by marine bivalves, thus, risk of entering environmental food chains (i.e., up to $340 \mathrm{~Bq} \mathrm{~kg}^{-1} \mathrm{DW}$ in mussel soft tissues; Whitehead et al. 1988).

On the other hand, radioactive selenium ( $\mathrm{Se}$ ) is a widely known fission product of nuclear reactions. It can be released into the environment during several steps of the nuclear fuel cycle comprising NPP wastewaters and spent nuclear fuel, with recent research focusing specifically on ${ }^{79} \mathrm{Se}$ mobility (half-life of $\sim 10^{5}$ y) from waste storage and nuclear waste disposal areas (Aguerre and Frechou 2006; Asai et al. 2011; Hamed et al. 2017). Selenium is considered a highly soluble, mobile, biologically essential and toxic trace element with a more comprehensive biogeochemical cycle (e.g., Tan et al. 2016; Winkel 2016) than that of Te. Due to their overall chemical similarity (both chalcogens/Group 16 elements), the environmental behaviour of Te is generally assumed to be similar to that of Se (Belzile and Chen 2015).

Given the massive dispersion of past NPP accidental releases through both aquatic and atmospheric compartments, the development of management plans for hypothetical future accidental NPP events requires knowledge on radionuclide behaviour including adsorption kinetics under environmentallyrepresentative conditions. Worldwide, many NPPs are located on fluvial-estuarine systems, for which little is known on Te (Wu et al. 2014; Duan et al. 2014; Biver et al. 2015) and Se (Measures and 
Burton 1978; Cutter 1989; Bizsel et al. 2017) environmental dispersion and biogeochemical behaviour.

This study aimed at determining Te and Se reactivity in estuarine salinity and turbidity gradients through isotopically-labelled sorption experiments (kinetics and isotherms) using natural bulk sediments and natural water matrices. Parallel selective extractions of particles previously exposed to isotopically-labelled $\mathrm{Te}$ and $\mathrm{Se}$ address solid fractionation for both, inherited and spiked concentrations. The results were further compared to dynamic environmental conditions (i.e., environmental timescales of semi-diurnal tidal variations, seasonal migration of the estuarine maximum turbidity zone, etc.). This comparison allowed to assess and predict for the first time the environmental fate and potential dispersion of short-lived Te vs long-lived Se radionuclides in case of a hypothetical accidental NPP liquid discharge in the fluvial-estuarine system of the Gironde Estuary (SW France hosting two NPPs: the Blayais NPP and the Golfech NPP, Gil-Díaz et al. 2018).

\section{Material and Methods}

\subsection{Experimental design}

Sorption experiments simulated four experimental conditions representative of the Gironde Estuary salinity and turbidity gradients: two contrasting water matrices (salinities 0 and 32) and two solid/liquid ratios (100 $\mathrm{mg} \mathrm{L}^{-1}$ and $\left.1000 \mathrm{mg} \mathrm{L}^{-1} \mathrm{DW}\right)$. Freshwater from the Garonne River and seawater from the Arcachon Bay, were filtered with $0.45 \mu \mathrm{m}$ Teflon filters (FHLC, Merck Millipore Ltd.). Freshwater sediments were sampled at Portets ( $30 \mathrm{~km}$ upstream from Bordeaux $)$ on the Garonne River. The water content was evaluated by comparing the masses of precise volumes of wet and dry sediment aliquots.

Spike solutions were prepared by dissolution of elemental ${ }^{125} \mathrm{Te}$ (99.89\% purity; Cortecnet, France) and ${ }^{77} \mathrm{Se}\left(99.20 \%\right.$ purity; Cortecnet, France) in $\mathrm{HCl}\left(2 \%\right.$ Suprapur®, Merck) and $\mathrm{HNO}_{3}(2 \%$ Suprapur®, Merck), respectively, heated at $70^{\circ} \mathrm{C}$ until dissolution. This method is known to produce oxidized species, i.e., well-known reaction for the formation of $\mathrm{Se}(\mathrm{VI})$ (Van Dael et al. 2004). Isotopically-labelled Te and Se solutions were further oxidised with $\mathrm{H}_{2} \mathrm{O}_{2}\left(30 \mu \mathrm{L} \mathrm{L}^{-1} 30 \%\right.$ J.T. Baker ultrapure) in the different water matrices to favour the oxidation state of ${ }^{125} \mathrm{Te}(\mathrm{VI})$ and ${ }^{77} \mathrm{Se}$ (VI) (e.g., Edwards et al. 1959; Horner and Leonard 1952), followed by an equilibration period of $24 \mathrm{~h}$. Slurries were prepared from the fresh sediments and unspiked water matrices and equilibrated during $24 \mathrm{~h}$, to avoid potential effects of sediment-water interactions during the sorption experiment (e.g., other ionic exchanges related to matrix properties influencing spiked Te or Se adsorption).

Sorption kinetics were performed with nominal concentrations of $5 \mu \mathrm{g} \mathrm{L}^{-1}$ of ${ }^{125} \mathrm{Te}(\mathrm{VI})$ and $100 \mu \mathrm{g}$ $\mathrm{L}^{-1}$ of ${ }^{77} \mathrm{Se}(\mathrm{VI})$. These spike concentrations are higher than those expected in most natural systems but 
were required for analytical purposes. All sorption experiments were performed in acid-washed $50 \mathrm{~mL}$ centrifuging polypropylene (PP) tubes with 3 replicates per experimental condition. Sorption experiments were placed on an automatic overhead shaker (REAX 20 Heidolph Instruments) and sampled at $\mathrm{t}=0,2,4,8,24$ and $48 \mathrm{~h}(\mathrm{~N}=3)$. These relatively short-term experimental conditions are considered to be in accordance with the environmental timescales of highly dynamic environments such as those occurring in continent-ocean transition systems. Temperature $\left(21.1 \pm 0.4^{\circ} \mathrm{C}\right), \mathrm{pH}(7.50 \pm$ 0.45 ) and oxic (104 $\pm 0.5 \%$ saturation) conditions, were monitored and remained stable throughout the experiment. In parallel, blank tubes containing only spiked water solutions were used to control ${ }^{125} \mathrm{Te}$ and ${ }^{77}$ Se potential losses onto PP walls over time.

Adsorption isotherms were performed for two SPM concentrations (100 mg L $\mathrm{m}^{-1}$ and $1000 \mathrm{mg} \mathrm{L}^{-1}$ ) with initial concentrations of dissolved ${ }^{125} \mathrm{Te}$ of $0.1,0.25,0.5,1,2.5,5 \mu \mathrm{g} \mathrm{L}^{-1}$ and initial concentrations of dissolved ${ }^{77} \mathrm{Se}$ of $0.5,5,10,25,50,75,100 \mu \mathrm{g} \mathrm{L}^{-1}(\mathrm{~N}=2)$ and sampled after $48 \mathrm{~h}$. Due to analytical constraints (i.e., salt tolerance of the ICP-MS), especially at the low concentration ranges, these experiments were only performed in freshwater conditions.

In both kinetics and isotherm experiments, dissolved $\mathrm{Te}\left(\mathrm{Te}_{\mathrm{d}}\right)$ and dissolved $\mathrm{Se}\left(\mathrm{Se}_{\mathrm{d}}\right)$ were monitored. Particulate concentrations were only determined for isotherm experiments using freshwater slurries with $1000 \mathrm{mg} \mathrm{L}^{-1}$ SPM for mass balance calculations. In all cases, the dissolved phase was separated from the particulate phase by centrifugation (10 min at $4000 \mathrm{rpm}$; Hettich Rotofix 32A centrifuge) and filtered ( $0.2 \mu \mathrm{m}$ Minisart ${ }^{\circledR}$ cellulose acetate) into acid-washed PP $15 \mathrm{~mL}$ tubes. These were then acidified with $\mathrm{HNO}_{3}(1 / 1000 \mathrm{v} / \mathrm{v} ;$ J.T. Baker ultrapure, $14 \mathrm{M})$ and stored at $4^{\circ} \mathrm{C}$ in the dark until analysis.

\subsection{Parallel selective extractions and total digestions}

High SPM concentrations $\left(2-4 \mathrm{~g} \mathrm{~L}^{-1} \mathrm{DW}\right)$ in freshwater $(\mathrm{S}=0)$ and seawater $(\mathrm{S}=32)$ were left to equilibrate for $48 \mathrm{~h}$ in spiked solutions of nominal $10 \mu \mathrm{g} \mathrm{L}^{-1}$ of ${ }^{125} \mathrm{Te}$ and $100 \mu \mathrm{g} \mathrm{L}^{-1}$ of ${ }^{77} \mathrm{Se}$. All sediments were recovered by centrifugation (Hettich ROTOFIX $32 \mathrm{~A})$, oven dried $\left(70^{\circ} \mathrm{C}\right.$, constant weight) and grinded in agate mortars, then aliquoted and extracted with parallel selective extractions (two replicates per extraction mode, Table 1). The targeted operationally defined solid fractions were: F1 - easily exchangeable and/or carbonate fraction (acetate solution extracting carbonates, Mn oxyhydroxides, sulphates and organic matter phases; Bordas and Bourg 1998; Kersten and Förstner 1987), F2 - reducible Fe/Mn oxides (ascorbate solution extracting Mn oxide and amorphous Fe oxide phases; Kostka and Luther 1994), F3 - oxidisable fraction $\left(\mathrm{H}_{2} \mathrm{O}_{2}\right.$ extraction of organic matter and labile/amorphous sulphide phases; Tessier et al. 1979; Ma et Uren 1995) and F4 - reactive and "potentially bioaccessible" fraction ( $\mathrm{HCl} 1 \mathrm{M}$ acid extraction of amorphous and crystalline $\mathrm{Fe}$ and $\mathrm{Mn}$ oxides, carbonates, amorphous monosulphurs and phyllosilicate phases; Huerta-Díaz and Morse 1990; 
Gasparon and Matschullat 2006). In addition to the latter, acid extraction with $\mathrm{HNO}_{3} 1 \mathrm{M}$ (F4N) was

140

141

142

143

144

145

146

147

148

149

150

151

152

153

154

155

156

157

158

159

160

161

162

163

164

165

166

167

168

169

170

171

172

173 performed on a separate aliquot to discard the $\mathrm{Cl}$ effect or specific acid effect on $\mathrm{F} 4$ obtained from $\mathrm{HCl} 1 \mathrm{M}$ leaching. All reagents used were of high purity grade except $\mathrm{H}_{2} \mathrm{O}_{2}$ (p.a. grade). High Te contamination of $\sim 35 \mathrm{\mu g} \mathrm{L}^{-1}$ was observed in the extraction blanks of $\mathrm{F} 3$ potentially from the $\mathrm{H}_{2} \mathrm{O}_{2}$ solution or the added ammonium acetate. This contamination is suspected to have been adsorbed into other than $\mathrm{H}_{2} \mathrm{O}_{2}$-extracted solid fractions (given the Te behaviour, see results), thus not affecting the inherited Te identified in $\mathrm{F} 3$ fraction. All extractions were performed in acid-washed $\left(\mathrm{HNO}_{3} 10 \%\right) \mathrm{PP}$ Falcon $50 \mathrm{~mL}$ conical centrifuge tubes (Fisher Scientific). Three blanks of each extraction were performed. Currently, no Certified Reference Materials (CRM) are available for Te and Se selective fractions. Residual fractions were calculated as the difference between the acid-soluble fraction (F4 or F4N) and the total adsorbed particulate concentration.

Total sediment concentrations were determined differently for particulate $\mathrm{Te}\left(\mathrm{Te}_{\mathrm{p}}\right)$ and particulate $\mathrm{Se}\left(\mathrm{Se}_{\mathrm{p}}\right)$. Mineralisation of sediment for Te analysis was achieved using a tri-acid digestion with $\mathrm{HNO}_{3}+\mathrm{HCl}+\mathrm{HF}$ as described elsewhere (e.g., Schäfer et al. 2002). Briefly, samples of $30 \mathrm{mg}$ were digested in closed PP tubes (DigiTUBEs ${ }^{\circledR}, \mathrm{SCP}$ Science) on a heating block $\left(2 \mathrm{~h}\right.$ at $\left.110^{\circ} \mathrm{C}\right)$ using 750 $\mu \mathrm{L} \mathrm{HNO}_{3}$ (14 M Suprapur®, Merck), $1.5 \mathrm{~mL} \mathrm{HCl} \mathrm{(10} \mathrm{M} \mathrm{Suprapur®,} \mathrm{Merck)} \mathrm{and} 2.5 \mathrm{~mL} \mathrm{HF} \mathrm{(29} \mathrm{M}$ Suprapur ${ }^{\circledR}$, Fisher). After an evaporation step at $120^{\circ} \mathrm{C}$, re-dissolution of the samples was performed with $250 \mu \mathrm{L} \mathrm{HNO}_{3}(14 \mathrm{M})$ and heating. After cooling, the samples were brought to $10 \mathrm{~mL}$ using MilliQ water (18.2 M $\Omega$ ).

For the analysis of $\mathrm{Se}_{\mathrm{p}}$ (volatile at $>70^{\circ} \mathrm{C}$, not compatible with the above-described tri-acid digestion) total microwave-assisted digestions (START 1500, MLS GmbH) were performed with 40 $50 \mathrm{mg}$ of sediment aliquots (Eiche et al. unpublished) already dried $\left(50^{\circ} \mathrm{C}\right.$ drying oven) and homogenised (agate mortar). Briefly, $3 \mathrm{~mL} \mathrm{HNO}_{3}$ (sub-boiled acid-distilled 65\%, p.a. grade, VWR Chemicals), $0.5 \mathrm{~mL} \mathrm{H}_{2} \mathrm{O}_{2}$ (30\% Rotipuran ${ }^{\circledR}$, Carl Roth), $0.25 \mathrm{~mL} \mathrm{HF}$ (40\% Suprapur®, Merck KGAA Darmstadt) and $0.5 \mathrm{~mL}$ ultrapure Milli-Q water were added. The temperature program was: $18^{\circ} \mathrm{C} \mathrm{min}{ }^{-1}$ to $75^{\circ} \mathrm{C}$, followed by $7^{\circ} \mathrm{C} \min ^{-1}$ to $110^{\circ} \mathrm{C}$, then $8^{\circ} \mathrm{C} \min ^{-1}$ to $150^{\circ} \mathrm{C}$ and $6^{\circ} \mathrm{C} \min ^{-1}$ to $210^{\circ} \mathrm{C}$, with a constant temperature of $210^{\circ} \mathrm{C}$ during $10 \mathrm{~min}$ before completely cooling down over night. After digestion, samples were transferred into PTFE vessels and evaporated on a hotplate to dryness at $70^{\circ} \mathrm{C}$ (no Se evaporation at this temperature), recovered with $270 \mu \mathrm{L}$ of $\mathrm{HNO}_{3}$ (65\% Suprapur), heated at $70^{\circ} \mathrm{C}$ for $1 \mathrm{~h}$ and made up with ultrapure Milli-Q water to a final volume of $6 \mathrm{~mL}$.

\subsection{Tellurium quantification}

Dissolved $\mathrm{Te}$ in samples from freshwater kinetics and isotherms experiments were directly analysed by ICP-MS (X-Series II, Thermo Fisher Scientific) using external calibration. Seawater matrices were diluted in $2 \% \mathrm{HNO}_{3}$ (J.T. Baker ultrapure, $14 \mathrm{M}$ ) and quantified with external 
calibration in an adapted salty matrix. In all cases, recoveries were between $85-91 \%$ for NIST $1643 f$ CRM (N=4) with a detection limit (LOD) of $0.01 \mu \mathrm{g} \mathrm{L}^{-1}(\mathrm{~N}=10)$. Given this LOD, the spiked concentrations and the dilution effect, it is assumed that pre-existing inherited ${ }^{125} \mathrm{Te}$ in the kinetics and isotherm samples is negligible in the water matrices as expected concentrations are in the range of $1 \mathrm{ng}$ $\mathrm{L}^{-1}$ (Filella 2013; Belzile and Chen 2015). The latter is corroborated by upstream freshwater analyses (Gil-Díaz et al. 2019a).

Digestates of particles from the isotherm experiments using $1000 \mathrm{mg} \mathrm{L}^{-1} \mathrm{SPM}$ in freshwater were quantified with an QQQ-ICP-MS (Agilent 8800, Basel, Switzerland) using an external calibration with ${ }^{103} \mathrm{Rh}$ as internal standard to correct for matrix effects. Tellurium was measured in oxygen-shift mode using $\mathrm{O}_{2}$ as collision gas $\left({ }^{125} \mathrm{Te}+{ }^{16} \mathrm{O} \rightarrow{ }^{141} \mathrm{TeO}\right)$. A certified reference material (NCS 73307) was used for quality check-up of the total digestions showing mean $\pm \mathrm{SD}$ recovery values of $94 \pm 17 \%(\mathrm{~N}=3)$.

Particulate Te in total digestions and selective extractions were quantified by TripleQuad-ICP-MS (TQ ICP-MS; iCAP-TQ, Thermo®) using external calibration. Given the very low inherited $\mathrm{Te}_{\mathrm{p}}$ concentrations $\left(\sim 0.04 \mathrm{mg} \mathrm{kg}^{-1}\right)$, natural/inherited $\mathrm{Te}\left(\mathrm{Te}_{\mathrm{nat}}\right)$ was quantified from ${ }^{126} \mathrm{Te}$ measured in KED-mode (He), correcting for ${ }^{86} \mathrm{Sr}^{40} \mathrm{Ar},{ }^{110} \mathrm{Cd}^{16} \mathrm{O}$ and ${ }^{110} \mathrm{Pd}^{16} \mathrm{O}$ interferences (Filella and Rodushkin 2018 ) with respective monoelemental solutions (influencing $<0.1 \%$ ) and ${ }^{126} \mathrm{Xe}$ from analytical blanks $\left(2 \% \mathrm{HNO}_{3}\right)$. Spiked/experimental ${ }^{125} \mathrm{Te}\left(\mathrm{Te}_{\mathrm{ex}}\right)$ was determined by TQ ICP-MS in mass-shift $\mathrm{O}_{2}$-mode (iCAP-TQ, Thermo®). Certified reference materials were used for instrumental quality check-up (freshwater NIST 1643f) and total digestions (stream sediment NCS 73307). Recoveries were $95 \pm 5 \%$ $(\mathrm{N}=5)$ in the KED-mode, $89 \pm 10 \%(\mathrm{~N}=5)$ in the $\mathrm{O}_{2}$-mode for NIST $1643 \mathrm{f}$ and $99 \pm 14 \%(\mathrm{~N}=4)$ in the KED-mode and $70 \pm 19 \%(\mathrm{~N}=4)$ in the $\mathrm{O}_{2}$-mode for NCS 73307. Inherited Te was quantified from both Te-spiked SPM and Se-spiked SPM (i.e., no influence from potential ${ }^{125} \mathrm{Te}$ spike effect). In selective extractions, $\mathrm{Te}_{\text {nat }}$ concentrations ranged from 5 -fold (in F2 extractions) to 200-fold (in F4 extractions) above LOD (0.1 $\left.\mathrm{ng} \mathrm{L}^{-1}, \mathrm{~N}=10\right)$.

\subsection{Selenium quantification}

Dissolved Se concentrations from sorption kinetics and isotherms were quantified by ICP-MS (XSeries 2, Thermo Fisher Scientific, KIT, Germany) using external calibration, CCT-mode (collision cell with $\mathrm{He}: \mathrm{H}_{2}$ mixture at $92 \%$ : $8 \%$ to minimise ${ }^{40} \mathrm{Ar}{ }^{37} \mathrm{Cl}$ interferences) and ${ }^{103} \mathrm{Rh} /{ }^{115} \mathrm{In}$ as internal standards. Analytical quality control was followed with certified drinking water (CRM-TMDW) and freshwater (NIST 1643f) standards showing recoveries ranging between $98-106 \%$ for the former $(\mathrm{N}=16)$ and $100-102 \%$ for the latter $(\mathrm{N}=16)$, with a LOD of $0.06 \mu \mathrm{g} \mathrm{L}^{-1}(\mathrm{~N}=10)$. Natural $\mathrm{Se}_{\mathrm{d}}$ concentrations were $0.14 \pm 0.03 \mu \mathrm{g} \mathrm{L}^{-1}$ in freshwater $(\mathrm{N}=32)$ and $\sim 0.31 \mu \mathrm{g} \mathrm{L}^{-1}$ for seawater (unpublished). 
Total ${ }^{77}$ Se digestions from the $1000 \mathrm{mg} \mathrm{L}^{-1} \mathrm{SPM}$ isotherm experiment were quantified by QQQICP-MS (Agilent 8800, Basel, Switzerland) using external calibration with ${ }^{103} \mathrm{Rh}$ as internal standard and oxygen-shift mode collision gas for ${ }^{77} \mathrm{Se}\left({ }^{77} \mathrm{Se}+{ }^{16} \mathrm{O} \rightarrow{ }^{93} \mathrm{SeO}\right)$ to avoid, amongst others, doubly charged Rare Earth Element (REE) interferences (mainly ${ }^{154} \mathrm{Sm}^{++},{ }^{154} \mathrm{Gd}^{++}$). The CRM NCS 73307 showed recoveries of total digestions ranging from 70 to $134 \%(\mathrm{~N}=3)$.

Analyses of $\mathrm{Se}$ in selective extractions, namely particulate inherited/natural $\mathrm{Se}\left(\mathrm{Se}_{\mathrm{nat}}\right)$ and spiked/experimental $\mathrm{Se}\left(\mathrm{Se}_{\mathrm{ex}}\right)$ were quantified with the $\mathrm{O}_{2}$-mode of the TQ ICP-MS (iCAP-TQ, Thermo ${ }^{\circledR}$ ) using external calibration, eliminating the known polyatomic interferences (e.g., ${ }^{40} \mathrm{Ar}^{37} \mathrm{Cl}$, ${ }^{154} \mathrm{Sm}^{++}$and ${ }^{154} \mathrm{Gd}^{++}$in ${ }^{77} \mathrm{Se},{ }^{78} \mathrm{Kr},{ }^{156} \mathrm{Gd}^{++}$and ${ }^{156} \mathrm{Dy}^{++}$in ${ }^{78} \mathrm{Se},{ }^{81} \mathrm{Br}^{1} \mathrm{H}$ and ${ }^{82} \mathrm{Kr}$ in ${ }^{82} \mathrm{Se}$ ) on both inherited $\left({ }^{78} \mathrm{Se},{ }^{80} \mathrm{Se},{ }^{82} \mathrm{Se}\right)$ and spiked $\left({ }^{77} \mathrm{Se}\right)$ isotopes. Particulate $\mathrm{Se}_{\text {nat }}$ was quantified from both Te-spiked and Se-spiked slurries. Analytical quality check showed recoveries of $95 \pm 3 \%$ for NIST $1643 \mathrm{f}$ and $85 \pm$ $2 \%$ for NIST $1640 \mathrm{a}$. Total adsorbed $\mathrm{Se}_{\mathrm{ex}}$ was calculated from the difference between initially spiked and final $\mathrm{Se}_{\mathrm{d}}$ after $48 \mathrm{~h}$.

\subsection{Distribution coefficient $(\mathrm{Kd})$}

Tellurium and Se partitioning between dissolved and particulate concentrations was evaluated from the kinetic experiments at equilibrium by using the particle-water distribution coefficient $(\mathrm{Kd})$, described in Sung (1995). Briefly, $\mathrm{Kd}$ (in $\left.\mathrm{L} \mathrm{kg}^{-1}\right)$ is the particulate $\left(\mathrm{mg} \mathrm{kg}^{-1}\right)$ to dissolved $\left(\mathrm{mg} \mathrm{L}^{-1}\right)$ concentration ratio (Equation 1). The relative contribution of the particulate concentration $\left(\mathrm{X}_{\mathrm{p}}\right)$ of a given element $\mathrm{X}$ to the total (dissolved + particulate) concentration of the same element $\left(\mathrm{X}_{\mathrm{T}}\right.$, Equation $2)$ is expressed as the fraction of $X_{p}\left(F_{p}\right.$, expressed in percentage, Equation 3).

$$
\mathrm{F}_{\mathrm{p}}(\%)=\left(\mathrm{X}_{\mathrm{p}} \cdot \mathrm{SPM}\right) / \mathrm{X}_{\mathrm{T}}=\left(\mathrm{K}_{\mathrm{d}} \cdot \mathrm{SPM}\right) /\left(1+\mathrm{K}_{\mathrm{d}} \cdot \mathrm{SPM}\right)
$$

where $X_{p}$ is expressed in $\mathrm{mg} \mathrm{kg}^{-1}, \mathrm{X}_{\mathrm{d}}$ in $\mathrm{mg} \mathrm{L}^{-1}, \mathrm{X}_{\mathrm{T}}$ in $\mathrm{mg} \mathrm{L}^{-1}$ and SPM in $\mathrm{kg} \mathrm{L}^{-1}$. This Kd should also match the slope of the isotherm experiments.

\subsection{Adsorption isotherm models}

The exchange of a substance between the dissolved and particulate phases reaches a dynamic equilibrium (i.e., equal sorption and desorption rates) after sufficient contact time (Foo and Hameed 
mechanisms (i.e., physisorption vs chemisorption), surface properties and sorption strength (Foo and Hameed 2010, and references therein).

The Langmuir empirical model is the most common two-parameter isotherm employed to describe monolayer chemical saturation onto finite sites with no lateral interactions between adsorbed molecules (no "steric hindrance"; Langmuir 1918). The mathematical equation for the Langmuir isotherm (Equation 4) is complemented with the dimensionless constant $\left(\mathrm{R}_{\mathrm{L}}\right)$ also known as the separation factor or equilibrium parameter (Equation 5) defined by Weber and Chakravorti (1974):

$$
\begin{gathered}
\mathrm{X}_{\mathrm{p}}=\left(\mathrm{X}_{\mathrm{pmax}} \cdot \mathrm{K}_{\mathrm{L}} \cdot \mathrm{X}_{\mathrm{d}}\right) /\left(1+\mathrm{K}_{\mathrm{L}} \cdot \mathrm{X}_{\mathrm{d}}\right) \\
\mathrm{R}_{\mathrm{L}}=1 /\left(1+\mathrm{K}_{\mathrm{L}} \cdot \mathrm{X}_{\mathrm{d} 0}\right)
\end{gathered}
$$

where $X_{p}$ is the concentration of element $X$ in the particulate phase at equilibrium ( $\mathrm{mg} \mathrm{kg}^{-1}$ ), calculated from the difference in dissolved concentrations between the initial spiked $\left(\mathrm{X}_{\mathrm{d} 0}\right)$ and the equilibrium $\left(\mathrm{X}_{\mathrm{d}}\right)$ concentrations $\left(\mu \mathrm{g} \mathrm{L}^{-1}\right.$, converted to particulate concentrations with the corresponding SPM ratio), $\mathrm{X}_{\mathrm{pmax}}$ is the maximum charge of $\mathrm{X}$ in the $\mathrm{SPM}$ and $\mathrm{K}_{\mathrm{L}}$ is the constant of Langmuir $\left(\mathrm{L} \mathrm{g}^{-1}\right)$. Values of $R_{L}$ indicate the adsorption nature of the isotherm as unfavourable $\left(R_{L}>1\right.$; i.e., highly soluble elements), linear $\left(R_{L}=1\right)$, favourable $\left(0<R_{L}<1\right)$ and irreversible $\left(R_{L}=0\right.$; i.e., high affinity for the particulate phase; Weber and Chakravorti 1974).

The Freundlich empirical model was the first one to describe heterogeneous (i.e., non-uniform distribution) multilayer adsorption on a non-homogeneous surface (Freundlich 1907). The mathematical expression of the Freundlich isotherm (Equation 6) represents the adsorption intensity by the $\mathrm{K}_{\mathrm{F}}$ constant (i.e., the higher the value the higher the affinity for the particulate phase) and the surface heterogeneity with the c value (i.e., the closer to zero the more heterogeneous; Foo and Hameed 2010). When $c=1$, the relationship between $X_{p}$ and $X_{d}$ is linear and $K_{F}=K d$ (distribution coefficient).

$$
\mathrm{X}_{\mathrm{p}}=\mathrm{K}_{\mathrm{F}} \cdot \mathrm{X}_{\mathrm{d}}^{\mathrm{c}}
$$

\section{Results}

\subsection{Tellurium sorption kinetics and isotherms}

Sorption kinetics of dissolved $\mathrm{Te}\left(\mathrm{Te}_{\mathrm{ex}}\right)$ was rapid (>40\% in less than 3 min., Figure 1a) independent from salinity, but highly dependent on the solid/liquid ratios, showing $\sim 90 \%$ sorption in $1000 \mathrm{mg} \mathrm{L}^{-1} \mathrm{SPM}$ within $3 \mathrm{~min}$. Equilibrium between the dissolved and particulate phases was achieved at $\geq 48 \mathrm{~h}$ in $100 \mathrm{mg} \mathrm{L}^{-1} \mathrm{SPM}$ and in $<5 \mathrm{~h}$ for $1000 \mathrm{mg} \mathrm{L}^{-1} \mathrm{SPM}$ (Figure 1a). Experimental blanks (i.e., no SPM) showed no measurable $\mathrm{Te}_{\mathrm{ex}}$ loss or adsorption onto tube walls throughout the 
whole experiment duration. Estimated particulate concentrations were used to calculate partitioning coefficients for $\mathrm{Te}_{\mathrm{ex}}$ at $48 \mathrm{~h}$ of adsorption time, showing $\log _{10} \mathrm{Kd}$ values in freshwater of $4.94 \pm 0.02 \mathrm{~L}$ $\mathrm{kg}^{-1}$ for $100 \mathrm{mg} \mathrm{L}^{-1}$ and $5.31 \pm 0.01 \mathrm{~L} \mathrm{~kg}^{-1}$ for $1000 \mathrm{mg} \mathrm{L}^{-1}$, whereas in seawater Kd values were $4.98 \pm$ $0.02 \mathrm{~L} \mathrm{~kg}^{-1}$ for $100 \mathrm{mg} \mathrm{L}^{-1}$ and $4.96 \pm 0.09 \mathrm{~L} \mathrm{~kg}^{-1}$ for $1000 \mathrm{mg} \mathrm{L}^{-1}$.

Sorption isotherms showed non-linear correlations at low SPM concentrations (100 $\mathrm{mg} \mathrm{L}^{-1}$, Figure 1b) following a Langmuir isotherm. Langmuir parameters were $K_{L}=3.91 \mathrm{~L} \mathrm{\mu g}^{-1}$ and b $=50.7 \mathrm{mg} \mathrm{kg}^{-1}$ with a separation factor of "favourable" to "very favourable" due to $\mathrm{R}_{\mathrm{L}}$ variations between 0.72 and 0.05. Nevertheless, higher SPM content of $1000 \mathrm{mg} \mathrm{L}^{-1}$ showed a linear behaviour representative of a Freundlich isotherm (Figure 1c) with relatively low heterogeneity $(\mathrm{c}=1)$. The value of $\sim 0.02 \mathrm{mg} \mathrm{kg}^{-1}$ at the intercept represented the inherited Te in the SPM, thus, included in the $\mathrm{Te}_{\mathrm{p}}$ concentrations. Calculated $\mathrm{Te}_{\mathrm{p}}$ concentrations were in accordance with directly analysed $\mathrm{Te}_{\mathrm{p}}(<15 \%$ difference, within analytical error) from $1000 \mathrm{mg} \mathrm{L}^{-1}$ experimental isotherm sediments.

\subsection{Selenium sorption kinetics and isotherms}

Selenium sorption kinetics ( $\mathrm{Se}_{\mathrm{ex}}$, Figure 2a) was less rapid than that of $\mathrm{Te}_{\mathrm{ex}}$ (Figure 1a), showing $<10 \%$ sorption after $3 \mathrm{~min}$ of exposure. There seems to be an effect of both salinity (i.e., higher sorption in seawater) and SPM concentration (i.e., higher sorption in $1000 \mathrm{mg} \mathrm{L}^{-1}$ ), reaching solid/liquid equilibrium in $<24 \mathrm{~h}$ for $1000 \mathrm{mg} \mathrm{L}^{-1}$ with max. $25 \%$ sorption. Precise sorption kinetics and equilibrium time for $100 \mathrm{mg} \mathrm{L}^{-1}$ (max. 5\% sorption) were uncertain, as all $\mathrm{Se}_{\mathrm{d}}$ values were close to the experimental blank concentrations with $4 \%$ variability shown by the standard deviation. Experimental blanks showed no measurable ${ }^{77} \mathrm{Se}$ loss or adsorption onto tube walls along the experiment. Estimated $\log _{10} \mathrm{Kd}$ values at $48 \mathrm{~h}$ were: $2.51 \pm 0.08 \mathrm{~L} \mathrm{~kg}^{-1}$ for $100 \mathrm{mg} \mathrm{L}^{-1}$ and $2.42 \pm 0.04 \mathrm{~L} \mathrm{~kg}^{-1}$ for $1000 \mathrm{mg} \mathrm{L}^{-1}$ in freshwater, whereas in seawater they were $2.87 \pm 0.10 \mathrm{~L} \mathrm{~kg}^{-1}$ for $100 \mathrm{mg} \mathrm{L}^{-1}$ and $2.57 \pm 0.04 \mathrm{~L} \mathrm{~kg}^{-1}$ for $1000 \mathrm{mg} \mathrm{L}^{-1}$.

Sorption isotherms for both SPM conditions (100 mg L-1 and $\left.1000 \mathrm{mg} \mathrm{L}^{-1}\right)$ showed similar concentrations and linear correlations, representative of a Freundlich isotherm (Figure 2b). The value at the intercept of $\sim 0.26 \mathrm{mg} \mathrm{kg}^{-1}$ represented inherited Se included in the $\mathrm{Se}_{\mathrm{p}}$ values. Calculated $\mathrm{Se}_{\mathrm{p}}$ concentrations tended to be $\sim 30 \%$ higher than those directly measured for $1000 \mathrm{mg} \mathrm{L}^{-1} \mathrm{SPM}$ isotherm samples.

\subsection{Selective extractions}

Selective extractions from both freshwater $(S=0)$ and seawater $(S=32)$ experiments of independent ${ }^{125} \mathrm{Te}$ and ${ }^{77} \mathrm{Se}$ spikes showed differences between spiked and inherited concentrations as well as 
distinct fractionation patterns for both elements (Figure 3). Relative contributions of each extracted fraction to total (inherited or spiked) Te and Se concentrations were expressed in percentages (Figure 3). Total concentrations used for Te calculations were $0.05 \mathrm{mg} \mathrm{kg}^{-1}$ for Te $\mathrm{nat}_{\text {thereas }} 2.68 \mathrm{mg} \mathrm{kg}^{-1}$ in $\mathrm{S}=0$ and $3.20 \mathrm{mg} \mathrm{kg}^{-1}$ in $\mathrm{S}=32$ for respective $\mathrm{Te}_{\mathrm{ex}}$ concentrations. Total $\mathrm{Se}_{\mathrm{nat}}$ concentrations ranged between $0.37-0.53 \mathrm{mg} \mathrm{kg}^{-1}$ and average $\mathrm{Se}_{\mathrm{ex}}$ was $25.7 \mathrm{mg} \mathrm{kg}^{-1}$ in both, freshwater and seawater.

The acid-soluble fractions showed the highest $\mathrm{Te}_{\mathrm{nat}}$ contribution $(\sim 50 \%$ in $\mathrm{F} 4$ and $\sim 30 \%$ in $\mathrm{F} 4 \mathrm{~N}$, Figure 3a) for freshwater experiments and were 10-20\% lower in seawater experiments. Average $\mathrm{Te}_{\text {nat }}$ contribution was $14 \%$ in the $\mathrm{H}_{2} \mathrm{O}_{2}$ fraction ( $\mathrm{F} 3$, associated to organic matter), <2\% in both, the easily exchangeable or carbonate fractions (F1) and the amorphous Mn/Fe oxide fraction (F2; Figure 3a). In contrast, $\mathrm{Te}_{\mathrm{ex}}$ sorbed preferentially (average $\sim 60 \%$ ) to the acid-soluble mineral phases (F4-F4N), comprising amorphous and crystalline $\mathrm{Fe}$ and Mn oxides, carbonates, amorphous monosulphurs (e.g., acid volatile sulphides and $\mathrm{FeS}$ ) and phyllosilicate phases. The latter also implies a $\sim 40 \%$ retention of $\mathrm{Te}_{\mathrm{ex}}$ in the residual fraction. Up to $10 \%$ of $\mathrm{Te}_{\mathrm{ex}}$ was sorbed in the F1-acetate (easily exchangeable or carbonates fraction) and $\mathrm{F} 2$-ascorbate ( $\mathrm{Mn} / \mathrm{Fe}$ oxides) extracted fractions, obtaining a lower, $<0.2 \%$ extraction with the oxidisable fraction $\left(\mathrm{F} 3-\mathrm{H}_{2} \mathrm{O}_{2}\right.$ organic matter and labile/amorphous sulphide phases). In any case, low differences $(\sim 5 \%)$ were observed between freshwater-adsorbed and seawater-adsorbed $\mathrm{Te}_{\mathrm{ex}}$ except for acid-soluble fractions where this difference varied from 20 to $30 \%$.

Selective extractions for $\mathrm{Se}_{\text {nat }}$ showed highest contributions $(\geq 85 \%)$ in the $\mathrm{F} 3-\mathrm{H}_{2} \mathrm{O}_{2}$ fraction (targeting organic matter and labile/amorphous sulphide phases) of SPM exposed to contrasting salinities (Figure 3b). Acid-soluble fractions obtained from $1 \mathrm{M} \mathrm{HCl}$ showed 2-fold lower $\mathrm{Se}_{\text {nat }}$ extractions than $1 \mathrm{M} \mathrm{HNO}_{3}$. Ascorbate solutions extracted concentrations of $\mathrm{Se}_{\text {nat }}$ similar to that of $\mathrm{HCl}$-extracted aliquots, and the lowest $\mathrm{Se}_{\text {nat }}$ fractions occurred in acetate extractions ( 1\%, Figure $\left.3 b\right)$. Spiked concentrations were also highly extracted in the $\mathrm{F} 3-\mathrm{H}_{2} \mathrm{O}_{2}$ fraction, representing $95-105 \%$ of total sorbed $\mathrm{Se}_{\mathrm{ex}}$. Noteworthy, the second most important fraction was the F2-ascorbate fraction, extracting $\sim 60 \%$ of $\mathrm{Se}_{\mathrm{ex}}$, presumably from amorphous $\mathrm{Mn} / \mathrm{Fe}$ oxide mineral phases. This amount of $\mathrm{Se}_{\mathrm{ex}}$ extracted was higher than that in the acid-soluble fractions F4 and F4N, both extracting $20 \%$ of $\mathrm{Se}_{\mathrm{ex}}$. Only $12 \%$ of $\mathrm{Se}_{\mathrm{ex}}$ was leached in the easily exchangeable/carbonate fraction (F1-acetate extraction). Differences between freshwater-adsorbed and seawater-adsorbed $\mathrm{Se}_{\mathrm{ex}}$ were $<10 \%$.

\section{Discussion}

\subsection{Tellurium reactivity and solid fractionation in estuarine salinity and turbidity gradients}

Results from sorption isotherms suggest a relatively high Te affinity for the particulate phases, as previously reported for Te radionuclides (Whitehead et al. 1988) and natural Te in the Changjiang Estuary (Wu et al. 2014). The observed $\log _{10} \mathrm{Kd}$ values for experimentally adsorbed Te are similar to 
typical Te $\log _{10} \mathrm{Kd}$ values in the Garonne-Gironde fluvial-estuarine system (Gil-Díaz et al. 2019a) ranging from 4.9 to $5.3 \mathrm{~L} \mathrm{~kg}^{-1}$. These values are up to one order of magnitude greater than those of natural As $\left(3.5-4.8 \mathrm{~L} \mathrm{~kg}^{-1}\right)$ and $\mathrm{Sb}\left(3.8\right.$ - $4.8 \mathrm{~L} \mathrm{~kg}^{-1}$; Gil-Díaz et al. 2018) suggesting that the solubility/mobility of both natural and experimentally adsorbed Te is lower than that of natural As and Sb. Experimentally adsorbed Se showed even lower partitioning $\left(2.4-2.9 \mathrm{~L} \mathrm{~kg}^{-1}\right.$, this study) with $\sim 2$ orders of magnitude lower than those of Te, suggesting that Se and Te solubility in environmental matrices may be very different.

Tellurium partitioning may also be compared to that of Cs, given (i) their potential common sources from weathering/remobilisation processes in the watershed (Gil-Díaz et al. 2019a), and (ii) their considerable radioactivity after accidental events (Steinhauser et al. 2014), making them relevant for radionuclide dispersion models. While the observed Te partitioning suggests relatively constant $\log _{10} \mathrm{Kd}$ of $\sim 4.9 \mathrm{~L} \mathrm{~kg}^{-1}$, the reported $\mathrm{Cs} \log _{10} \mathrm{Kd}$ values range from $<4.7 \mathrm{~L} \mathrm{~kg}^{-1}$ in river systems (Ciffroy et al. 2009) to typical values of $\log _{10} \mathrm{Kd} 5.1$ to $6.8 \mathrm{~L} \mathrm{~kg}^{-1}$ in the Garonne-Gironde fluvial system (Gil-Díaz et al. unpublished). Furthermore, Te $\log _{10} \mathrm{Kd}$ values are similar for both freshwater and seawater matrices with a maximum decrease of only $0.3 \mathrm{~L} \mathrm{~kg}^{-1}$ in the seawater, similar decreases to that observed for $\mathrm{Sb}$ in the Gironde Estuary (i.e., $0.2 \mathrm{~L} \mathrm{~kg}^{-1}$; Gil-Díaz et al. 2018). In contrast, the difference in $\mathrm{Cs} \log _{10} \mathrm{Kd}$ between freshwater and seawater is $1.4 \mathrm{~L} \mathrm{~kg}^{-1}$ under experimental conditions (Oughton et al. 1997). Therefore, one would expect only little desorption of Te along estuarine salinity gradients, compared to Cs mobilisation. This major difference in estuarine geochemical behaviour represents important information for the development of continent-ocean transition models anticipating potential $\mathrm{Te}$ and $\mathrm{Cs}$ radionuclide dispersion after accidental NPP releases. This observation also implies different biological transfers of Te and Cs, depending on the dissolved concentrations and bioaccessible fractions from the particle phase.

Assuming Te adsorption under natural conditions and at natural, low concentrations (i.e. less Te available for adsorption) one would expect the limited Te available to preferentially adsorb onto sites with high binding energy. Under experimental conditions, when relatively abundant dissolved $\mathrm{Te}$ exceed the number of strong binding sites, the different Te species would adsorb onto different sites, according to the respective binding strengths, starting with the high binding energy sites. However, the sorption isotherms of dissolved Te onto the particulate phase fits a Langmuir (chemisorption-driven) behaviour for both the low SPM ratio ( 100 $\mathrm{mg} \mathrm{L}^{-1}$; Figure 1b) and the high SPM condition (1000 mg $\mathrm{L}^{-1}$; Figure 1c), suggesting homogeneous monolayer adsorption of Te at equal bonding energy sites until saturation (Foo and Hameed 2010). This observation implies that, in the present experiment, the amount of dissolved Te available for adsorption did not exceed the number of strong bonding energy sites available, and thus may be representative of sorption processes under natural conditions. This saturation would be achieved at $\sim 50 \mathrm{mg} \mathrm{kg}^{-1}$ for Garonne River SPM which, together with kinetic results suggest that, in the maximum turbidity zone (MTZ) of the Gironde Estuary (SPM $\geq 1000 \mathrm{mg} \mathrm{L}$ - 
1; Sottolichio and Castaing 1999), a hypothetic $\mathrm{Te}_{\mathrm{d}}$ concentration of $50 \mu \mathrm{g} \mathrm{L}^{-1}$ could be retained to $\sim 90 \%$ within $<3$ min. Nearly all $\mathrm{Te}_{\mathrm{d}}(98 \%)$ would adsorb to the SPM in less than $2 \mathrm{~h}$ (Figure 1a). However, environmental concentrations of dissolved Te are found within the ultra-trace levels (e.g., Belzile and Chen 2015), and in the case of potential NPP accidents released Te masses would be expected to be orders of magnitude lower than those needed to reach saturation. In fact, a maximum of $68000000 \mathrm{~Bq} \mathrm{~m}^{-3}$ of ${ }^{137} \mathrm{Cs}$ (equivalent to $\sim 20 \mathrm{ng} \mathrm{L}^{-1}$ ) has been detected in early April in surface waters adjacent to the FDNPP, decreasing to $10000 \mathrm{~Bq} \mathrm{~m}^{-3}$ (equivalent to $\sim 3 \mathrm{pg} \mathrm{L}^{-1}$ ) in early 2012 (Buesseler et al. 2017). Therefore, assuming that the amounts of Te released would be similar in magnitude (or lower) than those of ${ }^{137} \mathrm{Cs}$, nearly all $\mathrm{Te}_{\mathrm{d}}$ radionuclides potentially released/produced in the Gironde Estuary would be highly retained in the particulate phase, even in seawater conditions. The latter is in accordance with the scavenged behaviour of Te observed in open ocean profiles of the Pacific and Atlantic Oceans, the East China Sea and the Angola and Panama Basins (Lee and Edmond 1985; Yoon et al. 1990; Wu et al. 2014).

The F4 acid-soluble fraction (attributed to the sum of amorphous and crystalline Fe and Mn oxides, carbonates, amorphous monosulphurs and phyllosilicate phases) is commonly considered to represent the fraction potentially bioaccessible to organisms (Australian and New Zealand sediment quality guidelines; ANZECC and ARMCANZ 2000). Based on this idea, the extractions suggest that $~ 30 \%$ of $\mathrm{Te}_{\text {nat }}$ in the SPM and $\sim 60 \%$ of the experimentally added $\mathrm{Te}_{\mathrm{ex}}$ retained in the particulate phase would be potentially bioaccessible. Accordingly, these fractions could impact filter-feeding organisms such as economically relevant bivalves (i.e., oysters) with unknown implications for the food chain. Interestingly, this observation also suggests that $\sim 40 \%$ of the experimentally adsorbed $\mathrm{Te}_{\mathrm{ex}}$ could not be recovered by $1 \mathrm{M}$ acid extraction, i.e. would be bound to the so-called residual fraction, typically attributed to minerals that are considered as relatively insoluble under respective conditions (Gupta and Chen 1975). Adsorption of $\mathrm{Te}_{\mathrm{ex}}$ to both, the bioacessible (60\%) and residual (40\%) fractions implies interaction with different mineral surfaces, which would not be consistent with the $\mathrm{Te}_{\mathrm{ex}}$ adsorption isotherm fitting the Langmuir model, unless different fractions showed relatively similar surface properties regarding Te sorption. Differences in Te dissolution between $1 \mathrm{M} \mathrm{HCl}(\mathrm{F} 4)$ and $1 \mathrm{M}$ $\mathrm{HNO}_{3}$-based (F4N) extractions ( 20\% higher in $\mathrm{HCl}$, Figure 3) observed for both naturally and experimentally-adsorbed Te, suggest that $\mathrm{HCl}$ may have stronger extraction efficiency than $\mathrm{HNO}_{3}$, although previous work has reported similar stability and solubility in both $\mathrm{HCl}$ and $\mathrm{HNO}_{3}$ solutions (Inorganic Ventures 2016).

Furthermore, these results appear to be in opposition with the higher Te adsorption observed in SPM in seawater conditions compared to that in freshwater (3.20 vs $2.70 \mathrm{mg} \mathrm{kg}^{-1}$, respectively). In fact, the relatively low acid-soluble extractions obtained from SPM exposed to seawater compared to freshwater conditions suggest that Te binds somehow strongly in seawater conditions (i.e., not related to easily exchangeable binding sites). This observation is in accordance with the observed negative 
correlation between the labile fraction of $\mathrm{Te}_{\mathrm{p}}$ and the salinity gradient in the Changjiang Estuary (Duan et al. 2014). Nevertheless, further research is required to verify these hypotheses and the specific binding modes of Te to amorphous and crystalline Fe and Mn oxides, amorphous monosulphurs and phyllosilicate phases.

Low extraction of $\mathrm{Te}_{\text {nat }}$ from the exchangeable/carbonate $(<10 \%$ in $\mathrm{F} 1)$, the amorphous $\mathrm{Fe} / \mathrm{Mn}$ oxide fraction $\left(<10 \%\right.$ in F2) and the organic matter fraction $\left(\sim 14 \%\right.$ in F3) are consistent with $\mathrm{Te}_{\text {nat }}$ extractions in marine SPM from the East China Sea (Duan et al. 2014). In fact, Duan et al. (2014) observed $13 \%$ and $11 \%$ Te in the exchangeable and carbonates fraction (i.e., from an acetate-solution extraction), $11 \%$ in the $\mathrm{Fe}-\mathrm{Mn}$ oxides (i.e., from a hydroxylamine-based solution) and $15 \%$ in the organic matter fraction (i.e., from $\mathrm{H}_{2} \mathrm{O}_{2}$-solution extraction), leaving $~ 50 \%$ in the so-called "residual" fraction. Similarly, the residual fraction (accounted as the difference between total Te and that in F4) of the Garonne River SPM carried $\sim 50 \%$ in freshwater-exposed SPM and $70 \%$ in seawater-exposed $\mathrm{SPM}$ of Te $\mathrm{ent}_{\text {nat }}$.

For the experimentally adsorbed $\mathrm{Te}_{\mathrm{ex}}$ simulating potential anthropogenic $\mathrm{Te}$ release into the natural environment the results suggest that up to $\sim 99 \%$ would be fixed onto SPM within few hours, depending on SPM concentrations. After sediment deposition in the estuarine banks and bed during tidal slacks, the onset of early diagenetic processes might potentially release (i) up to $10 \%$ of $\mathrm{Te}_{\mathrm{ex}}$ due to reductive dissolution of reactive $\mathrm{Fe}$ and $\mathrm{Mn}$ oxyhydroxides as simulated by ascorbate extractions (F2), and (ii) less than $1 \%$ of $\mathrm{Te}_{\mathrm{ex}}$ adsorbed to organic matter $\left(\mathrm{H}_{2} \mathrm{O}_{2}\right.$ extraction, F3). The relatively low F3 fraction obtained for $\mathrm{Te}_{\mathrm{ex}}$ compared to that of $\mathrm{Te}_{\mathrm{nat}}(14 \%)$ may suggest that Te physisorption or chemisorption onto particulate organic matter may be smaller than Te fixation by active incorporation (absorption). The observed results are applicable to Te(VI) sorption behavior, which is assumed to be representative of environmental conditions as $\mathrm{Te}(\mathrm{VI})$ is generally more abundant than $\mathrm{Te}(\mathrm{IV})$ in aquatic systems (Lee and Edmond 1985; Yoon et al. 1990), representing up to 5-fold the abundance of $\mathrm{Te}(\mathrm{IV})$ in the Changjiang Estuary (Wu et al. 2014). The precise Te species released to the environment after a NPP accident are unknown, potentially varying between events due to specific accident conditions. In fact, the presence and concentration of radionuclide species in the nuclear fuel depend on several factors including fuel composition and fuel burnup (Kleykamp 1985). Nevertheless, both $\mathrm{Te}(\mathrm{IV})$ and $\mathrm{Te}$ (VI) equally adsorb to Fe(III) hydroxides and Te(IV) to illite mineral phases (Harada and Takahashi 2009; Qin et al. 2017). Thus, this work may serve as a preliminary approach to radionuclide Te dispersion fate scenarios in the Gironde Estuary.

In a scenario of Te radionuclide dispersion after hypothetical NPP accidental events the above considerations suggest a dominant role of the estuarine SPM in Te retention and dispersion independent from the hydrological situation. Therefore, relatively few Te radionuclides would be bioavailable strongly limiting potential transfer to the atmosphere due to bio-methylation processes 
(Chasteen and Bentley 2003) within the estuarine reaches. Both, relatively low $\left(\sim 100 \mathrm{mg} \mathrm{L}^{-1}\right)$ and high (>1000 $\mathrm{mg} \mathrm{L}^{-1}$ ) SPM concentrations would result in almost total sequestration of Te due to adsorption of Te radionuclides on suspended particles. The environmental persistence of Te radionuclides depends on both, half-lives (e.g., ranging between 3.2 days for ${ }^{132} \mathrm{Te}$ to $\sim 3$ months for ${ }^{127 \mathrm{~m}} \mathrm{Te}$ for the most relevant ones) and fission yield (i.e., the probability of being produced from nuclear fission reactions). The combination of both parameters may result in estuarine Te radionuclide half-lives of several months. In any case, average particle residence times in the Gironde Estuary (1-2 years, Castaing and Jouanneau 1979), are clearly greater than the aforementioned radionuclide timescales, suggesting that the maximum decay would take place inside the estuary, except for specific hydrodynamic conditions allowing for massive particle expulsion to the coastal ocean (few days per year; Allen et al. 1980; Castaing and Allen 1981). The main decay products are radioactive or stable iodine daughter nuclides (e.g. ${ }^{129}$ I with $1.57 .10^{7}$ y half-life) which will then likely be mobilised to the water column (or pore waters) due to their relatively high solubility.

\subsection{Selenium reactivity and solid fractionation in estuarine salinity and turbidity gradients}

The experimentally determined sorption of Se onto SPM from the Garonne River is considerably lower than that of $\mathrm{Te}$, in accordance with the mobile character of Se in aquatic systems (FernándezMartínez and Charlet 2009). The corresponding Kd values ( $\log _{10} \mathrm{Kd}$ from 2.4 to $2.9 \mathrm{~L} \mathrm{~kg}^{-1}$ ) are in the low Kd range of values reported for natural (stable and radioactive) Se in estuarine/coastal systems such as the San Francisco Estuary $\left(\log _{10} \mathrm{Kd}\right.$ of $2.0-4.5 \mathrm{~L} \mathrm{~kg}^{-1}$ for $100 \mathrm{mg} \mathrm{L}^{-1} \mathrm{SPM}$; Benoit et al. 2010) and 19 Japanese coastal regions $\left(\log _{10} \mathrm{Kd}\right.$ of 2.6 - $3.9 \mathrm{~L} \mathrm{~kg}^{-1}$; Takata et al. 2016). In fact, differences between field $\mathrm{Kd}$ and experimental $\mathrm{Kd}$ for radionuclides have been also observed in environmental SPM samples (e.g., Co, Cs, Mn; Ciceri et al. 1988). These differences were explained by the contribution of the residual fraction to the calculation of field $\mathrm{Kd}$ (i.e., total digestions; Ciceri et al. 1988). Furthermore, Kd values are generally site-dependent as SPM mineralogy can strongly control elemental solid/liquid partitioning and Se Kd values have been observed to depend on grain size and organic matter (Takata et al. 2016). Sediments of the Gironde Estuary show characteristic particulate organic carbon (POC) contents ranging from 0.05 to 1.5\% (Etcheber et al. 2007; Coynel et al. 2016) and mainly contain silts and some sands (7 - $480 \mu \mathrm{m}$; Coynel et al. 2016).

Marine and estuarine environments generally present higher abundances of $\mathrm{Se}(\mathrm{VI})$ over $\mathrm{Se}(\mathrm{IV})$ (Cutter 1978; Cutter and Bruland 1984; Guan and Martin 1991). The observed Se(VI) adsorption kinetics fit a pseudo-second order reaction, suggesting that the main process involving $\mathrm{Se}(\mathrm{VI})$ removal from the solution are physicochemical interactions (physisorption) with rate-limiting chemisorption surfaces (Robati 2013). This sorption pattern is in accordance with bidentate outer-sphere and monodentate inner-sphere complexes reported for selenate adsorbed on ferric-Fe(III) (hydr-)oxides 
and clay minerals like kaolinite (Su and Suarez 2000; Peak and Sparks 2002; Nothstein 2016), despite the higher affinity of selenite (Se(IV)) inner-sphere complexes to these mineral phases (Hamdy and Gissel-Nielsen 1977; Hayes et al. 1987).

Such interactions are relatively weak reflecting the selective extractions results (Figure 3b), as more than half of the acid-soluble fraction (F4) is contributed by exchangeable Se forms (F1). This distribution of Se between several mineral phases is in line with $\mathrm{Se}(\mathrm{VI})$ sorption fitting Freundlich isotherms, implying heterogeneous sorption sites. In this case, stronger binding sites are occupied preferentially, decreasing the adsorption energy exponentially as they fill up (Zeldowitsch 1934). Weak interactions between dissolved $\mathrm{Se}(\mathrm{VI})$ and particle surfaces could be affected by ionic strength competition, decreasing Se(VI) sorption onto SPM (Su and Suarez 2000). However, the observed differences in Se sorption between freshwater- and seawater-exposed SPM fall within the analytical error.

Co-existing $\mathrm{Se}(\mathrm{IV})$ and $\mathrm{Se}(\mathrm{VI})$ forms may partly explain differences in parallel selective extractions of $\mathrm{Se}_{\text {nat }}$ and $\mathrm{Se}_{\mathrm{ex}}$. In fact, the selective extraction using oxidising reagents (i.e. the $\mathrm{F} 3-\mathrm{H}_{2} \mathrm{O}_{2}$ and the $\mathrm{F} 4 \mathrm{~N}-\mathrm{HNO}_{3}$ fractions; Figure 3c,d) generally show a high mobilisation of Se, probably due to the oxidation of $\mathrm{Se}(\mathrm{IV})$ to the more mobile $\mathrm{Se}(\mathrm{VI})$. Strong oxidants like $\mathrm{H}_{2} \mathrm{O}_{2}$, used to chemically oxidise the organic matter, as well as $\mathrm{HNO}_{3}$ compared to $\mathrm{HCl}$, can oxidise $\mathrm{Se}(\mathrm{IV}$ ) from carrier phases other than the target phase (Gruebel et al. 1988). Thus, although high Se content in the organic matter fraction would fit the nutrient type behaviour of Se in marine environments (e.g., Cutter and Bruland 1984, Cutter and Cutter 1995), the fact that the amount of Se extracted by $\mathrm{H}_{2} \mathrm{O}_{2}$ (F3) is close to $100 \%$ could also include Se extracted from other phases by oxidation (Figure 3), implying non-selectivity of the fractionation for Se. Sequential extractions in anoxic biofilms have also identified the nonselectivity of other oxidising reagents $(\mathrm{NaOCl})$ targeting Se in the "organically-associated" fraction for several inorganic/organic Se species (Lenz et al. 2008). The non-selectivity of both, $\mathrm{NaOCl}$ and $\mathrm{H}_{2} \mathrm{O}_{2}$ extractions of Se was already identified for soil and sediment extractions by Gruebel et al. (1988). These observations clearly suggest that commonly applied extraction schemes (e.g., Tessier et al. 1979; Ure et al. 1993) need to be updated and/or adapted before applied to specific elements, such as Se.

It is commonly accepted that the $1 \mathrm{M}$ acid-soluble fraction includes mineral phases extracted in the ascorbate fraction, thus trace element concentrations in F4 should be equal to or greater than in F2 fractions (Huerta-Díaz and Morse 1990; Kostka and Luther 1994; Gasparon and Matschullat 2006). The similar $\mathrm{Se}_{\text {nat }}$ concentrations in both $\mathrm{F} 4-\mathrm{HCl}$ and $\mathrm{F} 2$-ascorbate fractions (Figure 3d) are in accordance with this statement, potentially suggesting that most (if not all) of the $\mathrm{Se}_{n a t}$ in the $\mathrm{F} 4-\mathrm{HCl}$ fraction was extracted from the amorphous Fe/Mn oxide carrier phases (F2-ascorbate fraction). In contrast, $\mathrm{Se}_{\mathrm{ex}}$ was greater in the F2-ascorbate fraction than in the acid soluble fractions (F4 and F4N, 
Figure 3c). Interestingly, this effect of inversed extraction efficiency of parallel selective extractions (F2 vs F4) also occurred for both inherited and spiked Sb in the same SPM from the Garonne River (Gil-Díaz et al. 2019b). Thus, these results suggest an anomaly (compared to more commonly analysed elements such as $\mathrm{Cd}, \mathrm{Cu}, \mathrm{Zn}, \mathrm{Pb}$, etc.) for F2-ascorbate extractions of oxyanions like Se and $\mathrm{Sb}$, but not Te. This effect could be potentially due to strong organic complexation of Se and Sb by the citrate present in the ascorbate solution, thus extracting higher $\mathrm{Se}$ and $\mathrm{Sb}$ concentrations, independently from the dissolution of the targeted mineral carrier phase (Gil-Díaz et al. 2019b). These observations suggest that reducing conditions and the presence of strong organic ligands, as occurring in sub-oxic early diagenetic conditions (Froelich et al. 1979), potentially enhance Se $e_{e x}$ solubility, compared to $\mathrm{Se}_{\text {nat }}$.

Re-adsorption of Se (and As) onto non-targeted crystalline $\mathrm{Fe}$ hydroxides (i.e., goethite) is favoured during soil and sediment acid-based hydroxylamine extractions (reductive dissolution; Gruebel et al. 1988). Because acid $1 \mathrm{M} \mathrm{HCl}$ extractions do not dissolve crystalline Fe hydroxides such as goethite and hematite (Raiswell et al. 1994), one cannot exclude Se dissolution from target minerals and re-adsorption onto non-target minerals (e.g. crystalline $\mathrm{Fe}$ hydroxides) in $1 \mathrm{M} \mathrm{HCl}$ and $1 \mathrm{M} \mathrm{HNO}_{3}$ extractions. This effect implies that the estimation of the potentially bioaccessible Se fractions by acid extractions in sediments may be widely biased.

Combining the above findings, one would assume that, after a potential accidental release from NPPs in the Gironde Estuary, the majority of dissolved radioactive Se may be rapidly expulsed to the coastal ocean and $<30 \%$ retention in the particulate phase of the MTZ. Given the similarities between sorption isotherms and $\mathrm{Kd}$ at $100 \mathrm{mg} \mathrm{L}^{-1}$ and $1000 \mathrm{mg} \mathrm{L}^{-1} \mathrm{SPM}$ concentrations, dissolved Se probably is dominant for a wide range of SPM concentrations and dissolved radioactive Se releases. Moreover, reducing, suboxic conditions as existing in the MTZ water column (Robert et al. 2004) may further increase Se mobility due to leaching from particles subjected to early diagenetic processes.

Noteworthy, this expected dominance of dissolved Se radionuclides could enhance radioactivity transfer to the biological compartment, given the nutrient behaviour of Se (Tan et al. 2016). In fact, aquatic microorganisms naturally methylate Se as a part of their detoxifying mechanisms (Cooke and Bruland 1987). In the presence of Se radionuclides, bio-methylation processes might produce radioactive volatile Se (e.g., ${ }^{75} \mathrm{Se},{ }^{79} \mathrm{Se}$ and ${ }^{82} \mathrm{Se}$ ) species which must be taken into account for accidental dispersion scenarios. Such Se methylation is a seasonal process (i.e., low in winter and quantifiable in summer) with estimated average fluxes of the order of $10^{5} \mathrm{~g} \mathrm{y}^{-1}$ for the Gironde Estuary

546 (Amouroux and Donard 1997). Such methylation is species-dependent and can potentially show nonnegligible atmospheric dispersion (Luxem et al. 2015).

Thus, accidental releases of dissolved Se radionuclides such as ${ }^{75} \mathrm{Se}(\sim 119 \mathrm{~d}$ half-life $),{ }^{79} \mathrm{Se}\left(\sim 10^{5} \mathrm{y}\right.$ 
column (e.g. estuarine water residence times of 10 to 80 days), implying (i) continuous exportation of dissolved radioactive Se to the coast during winter/high discharge conditions, (ii) bio-availability to primary producers and the related food chain, and (iii) potential seasonal production of radioactive methylated species exported to the atmosphere.

\section{Conclusion}

Batch experiments with bulk SPM and natural freshwater/seawater matrices simulating contrasting estuarine turbidity and salinity gradients showed different sorption kinetics, particulate affinity and solid fractionation distribution for Te and Se. Experimental results strongly suggest that the fluvialestuarine geochemical cycles of Te and Se are not comparable in terms of reactivity, solubility and bioavailability. Further knowledge on $\mathrm{Te}$ speciation and sorption mechanisms is required in environmental studies.

The solid fractionation results suggest that anthropogenic releases of dissolved $\mathrm{Te}$ and $\mathrm{Se}$ to the aquatic environment do not fully mimic inherited element distribution among SPM mineral phases. The observed differences imply that (i) particulate $\mathrm{Te}_{\mathrm{ex}}$ is potentially more bioaccessible than the already present particulate $\mathrm{Te}_{\mathrm{nat}}$, and that (ii) $\mathrm{Se}_{\mathrm{ex}}$ may be more easily exchangeable and mobile during early diagenetic processes than $\mathrm{Se}_{\text {nat }}$. Comparison of $\mathrm{Se}$ solid partitioning with results of selective extractions commonly applied to other trace elements point out to two anomalies: (i) enhanced dissolution of Se species in oxidising conditions probably due to oxidation of $\mathrm{Se}(\mathrm{IV})$ to the more soluble $\mathrm{Se}(\mathrm{VI})$ and subsequent mobilisation from other solid carrier phases (non-selectivity), and (ii) potential extraction by dissolved organic complexants in addition to release from reducible mineral phases. These findings clearly show that the use of commonly applied extraction schemes to other than originally tested target elements may produce artefacts that need thorough evaluation and must be taken into account for environmental interpretations.

Preliminary dispersion scenarios of hypothetical releases of $\mathrm{Te}$ and $\mathrm{Se}$ radionuclides into the Garonne-Gironde fluvial-estuarine system suggest high potential adsorption of Te radionuclides onto estuarine SPM in all hydrological conditions (flood and drought). This implies long estuarine residence times for Te radionuclides (up to several months, in accordance with the half-life and activities of the radionuclides released), and the risk of seasonal upstream movement when a hypothetic accident happens in a period when the MTZ is located downstream in the estuary. In contrast, Se radionuclides would preferentially remain in the dissolved phase continuously exported to the coastal ocean within several weeks, implying a risk of transfer to primary producers and the related food chain including seafood. 


\section{Acknowledgements}

587

588

589

590

591

592

593

594

595

596

597

598

599

600

601

602

603

604

605

606

607

608

609

610

611

612

613

614

615

616

617

618

619

620

621

This study is a scientific contribution to the French National Project AMORAD (ANR-11-RSNR0002) from the National Research Agency, allocated in the framework program "Investments for the Future". The authors gratefully acknowledge the financial assistance of the FEDER Aquitaine-1999Z0061, the German Academic Exchange Service DAAD and the SNF Project 200021-178784.

\section{References}

Aguerre, S., Frechou, C. (2006). Development of a radiochemical separation for selenium with the aim of measuring its isotope 79 in low and intermediate nuclear wastes by ICP-MS. Talanta, 69(3), 565-571.

Allen, G. P., Salomon, J. C., Bassoullet, P., Du Penhoat, Y., De Grandpre, C. (1980). Effects of tides on mixing and suspended sediment transport in macrotidal estuaries. Sedimentary Geology, 26(13), 69-90.

Amouroux, D., Donard, O. F. (1997). Evasion of selenium to the atmosphere via biomethylation processes in the Gironde estuary, France. Marine Chemistry, 58(1-2), 173-188.

ANZECC and ARMCANZ (2000). Australian and New Zealand guidelines for fresh water and marine water quality. Australian and New Zealand Environment and Conservation Council/Agriculture and Resource Management Council of Australia and New Zealand, Canberra

Audry, S., Blanc, G., Schäfer, J. (2006). Solid state partitioning of trace metals in suspended particulate matter from a river system affected by smelting-waste drainage. Science of the Total Environment, 363(1-3), 216-236.

Asai, S., Hanzawa, Y., Okumura, K., Shinohara, N., Inagawa, J., Hotoku, S., Suzuki, K., Kaneko, S. (2011). Determination of 79Se and 135Cs in spent nuclear fuel for inventory estimation of highlevel radioactive wastes. Journal of Nuclear Science and Technology, 48(5), 851-854.

Baeza, A., Corbacho, J. A., Rodríguez, A., Galván, J., García-Tenorio, R., Manjón, G., Mantero, J., Vioque, I., Arnold, D., Grossi, C., Serrano, I., Vallés, I., Vargas, A. (2012). Influence of the Fukushima Dai-ichi nuclear accident on Spanish environmental radioactivity levels. Journal of Environmental Radioactivity, 114, 138-145.

Belzile, N., Chen, Y. W. (2015). Tellurium in the environment: A critical review focused on natural waters, soils, sediments and airborne particles. Applied Geochemistry, 63, 83-92.

Benoit, M. D., Kudela, R. M., Flegal, A. R. (2010). Modeled trace element concentrations and partitioning in the San Francisco estuary, based on suspended solids concentration. Environmental Science and Technology, 44(15), 5956-5963.

Biver, M., Quentel, F., Filella, M. (2015). Direct determination of tellurium and its redox speciation at the low nanogram level in natural waters by catalytic cathodic stripping voltammetry. Talanta, 144, 1007-1013. 
Bizsel, N., Ardelan, M. V., Bizsel, K. C., Suzal, A., Demirdag, A., Sarıca, D. Y., Steinnes, E. (2017). Distribution of selenium in the plume of the Gediz River, Izmir Bay, Aegean Sea. Journal of Marine Research, 75(2), 81-98.

Bordas, F., Bourg, A. C. (1998). A critical evaluation of sample pretreatment for storage of contaminated sediments to be investigated for the potential mobility of their heavy metal load. Water, Air, and Soil Pollution, 103(1-4), 137-149.

Buesseler, K., Dai, M., Aoyama, M., Benitez-Nelson, C., Charmasson, S., Higley, K., Maderich, V., Masqué, P., Morris, P.J., Oughton, D., Smith, J. N. (2017). Fukushima Daiichi-derived radionuclides in the ocean: transport, fate, and impacts. Annual Review of Marine Science, 9, 173203.

Castaing, P., Allen, G. P. (1981). Mechanisms controlling seaward escape of suspended sediment from the Gironde: a macrotidal estuary in France. Marine Geology, 40(1-2), 101-118.

Castaing, P., Jouanneau, J. M. (1979). Temps de résidence des eaux et des suspensions dans l'estuaire de la Gironde. Journal Recherche Océanographie IV, 41-52.

Chasteen, T. G., Bentley, R. (2003). Biomethylation of selenium and tellurium: microorganisms and plants. Chemical Reviews, 103(1), 1-26.

Ciceri, G., Traversi, A.L., Martinotti, W., Queirazza, G. (1988). Radionuclide partitioning between water and suspended matter: comparison of different methodologies. Studies in Environmental Science, 34, 353-375.

Ciffroy, P., Durrieu, G., Garnier, J. M. (2009). Probabilistic distribution coefficients (Kds) in freshwater for radioisotopes of $\mathrm{Ag}, \mathrm{Am}, \mathrm{Ba}, \mathrm{Be}, \mathrm{Ce}, \mathrm{Co}, \mathrm{Cs}, \mathrm{I}, \mathrm{Mn}, \mathrm{Pu}, \mathrm{Ra}, \mathrm{Ru}, \mathrm{Sb}, \mathrm{Sr}$ and Thimplications for uncertainty analysis of models simulating the transport of radionuclides in rivers. Journal of Environmental Radioactivity, 100(9), 785-794.

Cooke, T. D., Bruland, K. W. (1987). Aquatic chemistry of selenium: evidence of biomethylation. Environmental Science and Technology, 21(12), 1214-1219.

Coynel, A., Gorse, L., Curti, C., Schafer, J., Grosbois, C., Morelli, G., Ducassou, E., Blanc, G., Maillet, G.M., Mojtahid, M. (2016). Spatial distribution of trace elements in the surface sediments of a major European estuary (Loire Estuary, France): Source identification and evaluation of anthropogenic contribution. Journal of Sea Research, 118, 77-91.

Cutter, G. A. (1978). Species determination of selenium in natural waters. Analytica Chimica Acta, 98(1), 59-66.

Cutter, G. A. (1989). The estuarine behaviour of selenium in San Francisco Bay. Estuarine, Coastal and Shelf Science, 28(1), 13-34.

Cutter, G. A., Bruland, K. W. (1984). The marine biogeochemistry of selenium: A re-evaluation. Limnology and Oceanography, 29(6), 1179-1192.

Cutter, G. A., Cutter, L. S. (1995). Behavior of dissolved antimony, arsenic, and selenium in the Atlantic Ocean. Marine Chemistry, 49(4), 295-306.

Duan, L. Q., Song, J. M., Yuan, H. M., Li, X. G., Li, N., Ma, J. K. (2014). Distribution, chemical speciation and source of trace elements in surface sediments of the Changjiang Estuary. Environmental Earth Sciences, 72(8), 3193-3204. 
Edwards, J.O., Abbott, J.R., Ellison, H.R. and Nyberg, J. (1959). Coördination Number Changes during Oxidation-Reduction Reactions of Oxyanions. The Kinetics of the Aniline Nitrosation and of the Glycol-Tellurate Reaction. The Journal of Physical Chemistry, 63(3), 359-365.

Element Collection Inc.: Gray, T., Mann, N., Whitby, M. (2007). Periodic Table of Isotopes. http://periodictable.com/Isotopes/051.123/index.p.full.html (accessed on the 10 March 2015)

Etcheber, H., Taillez, A., Abril, G., Garnier, J., Servais, P., Moatar, F., Commarieu, M. V. (2007). Particulate organic carbon in the estuarine turbidity maxima of the Gironde, Loire and Seine estuaries: origin and lability. Hydrobiologia, 588(1), 245-259.

Fernández-Martínez, A., Charlet, L. (2009). Selenium environmental cycling and bioavailability: a structural chemist point of view. Reviews in Environmental Science and Bio/Technology, 8(1), 81110.

Filella, M. (2013). Food for thought: a critical overview of current practical and conceptual challenges in trace element analysis in natural waters. Water, 5(3), 1152-1171.

Filella, M., Rodushkin, I. (2018). A concise guide for the determination of less-studied technologycritical elements $(\mathrm{Nb}, \mathrm{Ta}, \mathrm{Ga}, \mathrm{In}, \mathrm{Ge}, \mathrm{Te})$ by inductively coupled plasma mass spectrometry in environmental samples. Spectrochimica Acta Part B: Atomic Spectroscopy, 141, 80-84.

Foo, K. Y., Hameed, B. H. (2010). Insights into the modeling of adsorption isotherm systems. Chemical Engineering Journal, 156(1), 2-10.

Freundlich, H. (1907). Über die adsorption in lösungen. Zeitschrift für physikalische Chemie, 57(1), 385-470. [Over the adsorption in solution, Journal of Physical Chemistry, 57, 385-471.]

Froelich, P., Klinkhammer, G. P., Bender, M. L., Luedtke, N. A., Heath, G. R., Cullen, D., Dauphin, P., Hammond, D., Hartman, B., Maynard, V. (1979). Early oxidation of organic matter in pelagic sediments of the eastern equatorial Atlantic: suboxic diagenesis. Geochimica et Cosmochimica Acta, 43(7), 1075-1090.

Gasparon, M., Matschullat, J. (2006). Trace metals in Antarctic ecosystems: results from the Larsemann Hills, East Antarctica. Applied Geochemistry, 21(9), 1593-1612.

Gil-Díaz, T., Schäfer, J., Coynel, A., Bossy, C., Dutruch, L., Blanc, G. (2018). Antimony in the LotGaronne river system: a 14-year record of solid-liquid partitioning and fluxes. Environmental Chemistry. DOI: 10.1071/EN17188

Gil-Díaz, T., Schäfer, J., Dutruch, L., Bossy, C., Pougnet, F., Abdou, M., Lerat-Hardy, A., Pereto, C., Derriennic, H., Briant, N., Sireau, T., Knoery, J., Blanc, G. (2019a). Tellurium behaviour in a major European fluvial-estuarine system (Gironde, France): fluxes, solid/liquid partitioning, and bioaccumulation in wild oysters. Environmental Chemistry. DOI: 10.1071/EN18226

Gil-Díaz, T., Schäfer, J., Filella, M., Dutruch, L., Bossy, C. (2019b). Fractionation of inherited and spiked antimony $(\mathrm{Sb})$ in fluvial/estuarine bulk sediments: Unexpected anomalies in parallel selective extraction protocols. Applied Geochemistry, 108, 104386 (DOI: 10.1016/j.apgeochem.2019.104386)

Gruebel, K. A., Leckie, J. O., Davis, J. A. (1988). The feasibility of using sequential extraction techniques for arsenic and selenium in soils and sediments. Soil Science Society of America Journal, 52(2), 390-397.

Guan, D. M., Martin, J. M. (1991). Selenium distribution in the Rhone delta and the Gulf of Lions. Marine Chemistry, 36(1-4), 303-316 
Gupta, S. K., Chen, K. Y. (1975). Partitioning of trace metals in selective chemical fractions of nearshore sediments. Environmental Letters, 10(2), 129-158.

Hamed, M. M., Holiel, M., El-Aryan, Y. F. (2017). Removal of selenium and iodine radionuclides from waste solutions using synthetic inorganic ion exchanger. Journal of Molecular Liquids, 242, $722-731$.

Hamdy, A. A., Gissel-Nielsen, G. (1977). Fixation of selenium by clay minerals and iron oxides. Zeitschrift für Pflanzenernährung und Bodenkunde, 140(1), 63-70.

Harada, T., Takahashi, Y. (2009). Origin of the difference in the distribution behavior of tellurium and selenium in a soil-water system. Geochimica et Cosmochimica Acta, 72(5), 1281-1294.

Hayes, K. F., Roe, A. L., Brown, G. E., Hodgson, K. O., Leckie, J. O., Parks, G. A. (1987). In situ Xray absorption study of surface complexes: Selenium oxyanions on $\alpha-\mathrm{FeOOH}$. Science, 238(4828), 783-786.

Horner, H. J., Leonard Jr, G. W. (1952). Preparation of Telluric Acid. Journal of the American Chemical Society, 74(14), 3694-3694.

Huerta-Díaz, M. A., Morse, J. W. (1990). A quantitative method for determination of trace metal concentrations in sedimentary pyrite. Marine Chemistry, 29, 119-144.

Inorganic Ventures (2016). https://www.inorganicventures.com (accessed on the 28 July 2018). Ishikawa, T. (2014). A brief review of dose estimation studies conducted after the Fukushima Daiichi Nuclear Power Plant accident. Radiation Emergency Medicine, 3, 21-27.

Izrael, Y.A. (2002). Radioactive fallout after nuclear explosions and accidents. Elsevier, Saint Louis.Kersten, M., Förstner, U. (1987). Cadmium associations in freshwater and marine sediment, in: Nriagu, J.O., Sprague, J.B. (Eds.), Cadmium in the Aquatic Environment, John Wiley \& Sons, Inc., pp. 51-88.

Kleykamp, H. (1985). The chemical state of the fission products in oxide fuels. Journal of Nuclear Materials, 131(2-3), 221-246.

Kostka, J. E., Luther III, G. W. (1994). Partitioning and speciation of solid phase iron in saltmarsh sediments. Geochimica et Cosmochimica Acta, 58(7), 1701-1710.

Langmuir, I. (1918). The adsorption of gases on plane surfaces of glass, mica and platinum. Journal of the American Chemical Society, 40(9), 1361-1403.

Lenz, M., Hullebusch, E. D. V., Farges, F., Nikitenko, S., Borca, C. N., Grolimund, D., Lens, P. N. (2008). Selenium speciation assessed by X-ray absorption spectroscopy of sequentially extracted anaerobic biofilms. Environmental Science and Technology, 42(20), 7587-7593.

Leppänen, A. P., Mattila, A., Kettunen, M., Kontro, R. (2013). Artificial radionuclides in surface air in Finland following the Fukushima Dai-ichi nuclear power plant accident. Journal of Environmental Radioactivity, 126, 273-283.

Lee, D. S., Edmond, J. M. (1985). Tellurium species in seawater. Nature, 313(6005), 782.

Luxem, K. E., Vriens, B., Wagner, B., Behra, R., Winkel, L. H. (2015, April). Selenium uptake and volatilization by marine algae. In EGU General Assembly Conference Abstracts (Vol. 17).

Ma, Y., Uren, N.C., (1995). Application of a new fractionation scheme for heavy metals in soils. Communications in Soil Science and Plant Analysis, 26, 3291-3303. 
Measures, C. I., Burton, J. D. (1978). Behaviour and speciation of dissolved selenium in estuarine waters. Nature, 273(5660), 293.

Morewitz, H. A. (1981). Fission product and aerosol behavior following degraded core accidents. Nuclear Technology, 53(2), 120-134.

Nothstein, A. K. (2016). Selenium Transfer between Kaolinite or Goethite Surfaces, Nutrient Solution and Oryza Sativa (Vol. 41). KIT Scientific Publishing.

Oughton, D. H., Børretzen, P., Salbu, B., Tronstad, E. (1997). Mobilisation of 137Cs and 90Sr from sediments: potential sources to arctic waters. Science of the Total Environment, 202(1-3), 155-165.

Peak, D., Sparks, D. L. (2002). Mechanisms of selenate adsorption on iron oxides and hydroxides. Environmental Science and Technology, 36(7), 1460-1466.

Qin, H.-B, Takeichi, Y., Nitani, H., Terada, Y., Takahashi, Y. (2017). Tellurium distribution and speciation in contaminated soils from abandoned mine tailings: comparison with selenium. Environmental Science and Technology, 51(11), 6027-6035.

Raiswell, R., Canfield, D.E., Berner, R.A., (1994). A comparison of iron extraction methods for the determination of degree of pyritization and the recognition of iron-limited pyrite formation. Chemical Geology, 111, 101-110.

Robati, D. (2013). Pseudo-second-order kinetic equations for modeling adsorption systems for removal of lead ions using multi-walled carbon nanotube. Journal of Nanostructure in Chemistry, 3(1), 55 .

Robert, S., Blanc, G., Schäfer, J., Lavaux, G., Abril, G. (2004). Metal mobilization in the Gironde Estuary (France): the role of the soft mud layer in the maximum turbidity zone. Marine Chemistry, 87(1-2), 1-13.

Saegusa, J., Kikuta, Y., Akino, H. (2013). Observation of gamma-rays from fallout collected at Ibaraki, Japan, during the Fukushima nuclear accident. Applied Radiation and Isotopes, 77, 56-60.

Schäfer, J., Blanc, G., Lapaquellerie, Y., Maillet, N., Maneux, E., Etcheber, H. (2002). Ten-year observation of the Gironde tributary fluvial system: fluxes of suspended matter, particulate organic carbon and cadmium. Marine Chemistry, 79, 229-242.

Sonzogni, A.A. (2013). Chart of Nuclides NuDat 2.6 - National Nuclear Data Center. Brookhaven National Laboratory. http://www.nndc.bnl.gov/nudat2/reCenter.jsp?z=51\&n=68 (accessed on the 10 March 2015).

Sottolichio, A., Castaing, P. (1999). A synthesis on seasonal dynamics of highly-concentrated structures in the Gironde estuary. Comptes Rendus de l'Académie des Sciences-Series IIA-Earth and Planetary Science, 329(11), 795-800.

Steinhauser, G., Brandl, A., Johnson, T.E. (2014). Comparison of the Chernobyl and Fukushima nuclear accidents: A review of the environmental impacts. Science of the Total Environment, 470471, 800-817.

Su, C., Suarez, D. L. (2000). Selenate and selenite sorption on iron oxides an infrared and electrophoretic study. Soil Science Society of America Journal, 64(1), 101-111.

Sung, W. (1995). Some observations on surface partitioning of $\mathrm{Cd}, \mathrm{Cu}$ and $\mathrm{Zn}$ in estuaries. Environmental Science and Technology, 29, 1303. 
Tan, L. C., Nancharaiah, Y. V., van Hullebusch, E. D., Lens, P. N. (2016). Selenium: environmental significance, pollution, and biological treatment technologies. Biotechnology Advances, 34(5), 886-907.

Takata, H., Aono, T., Tagami, K., Uchida, S. (2016). A new approach to evaluate factors controlling elemental sediment-seawater distribution coefficients (Kd) in coastal regions, Japan. Science of the Total Environment, 543, 315-325.

Tessier, A., Campbell, P. G., Bisson, M. (1979). Sequential extraction procedure for the speciation of particulate trace metals. Analytical Chemistry, 51(7), 844-851.

Ure, A. M., Quevauviller, P., Muntau, H., Griepink, B. (1993). Speciation of heavy metals in soils and sediments. An account of the improvement and harmonization of extraction techniques undertaken under the auspices of the BCR of the Commission of the European Communities. International Journal of Environmental Analytical Chemistry, 51(1-4), 135-151.

Van Dael, P., Lewis, J. and Barclay, D. (2004). Stable isotope-enriched selenite and selenate tracers for human metabolic studies: a fast and accurate method for their preparation from elemental selenium and their identification and quantification using hydride generation atomic absorption spectrometry. Journal of Trace Elements in Medicine and Biology, 18(1), 75-80.

Weber, T. W., Chakravorti, R. K. (1974). Pore and solid diffusion models for fixed-bed adsorbers. American Institute of Chemical Engineers Journal, 20(2), 228-238.

Whitehead, N. E., Ballestra, S., Holm, E., Huynh-Ngoc, L. (1988). Chernobyl radionuclides in shellfish. Journal of Environmental Radioactivity, 7(2), 107-121.

Winkel, L. H. (2016). The global biogeochemical cycle of selenium: Sources, fluxes and the influence of climate. In Global Advances in Selenium Research from Theory to Application: Proceedings of the 4th International Conference on Selenium in the Environment and Human Health (pp. 3-4). CRC Press/Balkema.

Wu, X., Song, J., Li, X. (2014). Occurrence and distribution of dissolved tellurium in Changiiang River estuary. Chinese Journal of Oceanology and Limnology, 32(2), 444-454.

Yoon, B. M., Shim, S. C., Pyun, H. C., Lee, D. S. (1990). Hydride generation atomic absorption determination of tellurium species in environmental samples with in situ concentration in a graphite furnace. Analytical Sciences, 6(4), 561-566.

Zeldowitsch, J. (1934). Adsorption site energy distribution. Acta Physicochimica URSS, 1, 961-973. 


\section{Figure captions:}

Figure 1. Sorption of tellurium in natural SPM. (a) Te sorption kinetics $(\mathrm{N}=3)$ in freshwater (empty symbols) and seawater (filled symbols) matrices for $100 \mathrm{mg} \mathrm{L}^{-1}$ (triangles) and $1000 \mathrm{mg}$ $\mathrm{L}^{-1}$ (circles) SPM content. Adsorption percentages are calculated as the difference between initial spiking concentration and $\mathrm{Te}_{\mathrm{d}}$ at each sampling time. Tellurium isotherms $(\mathrm{N}=2$, after $48 \mathrm{~h}$ equilibration) for (b) freshwater sorption in $100 \mathrm{mg} \mathrm{L}^{-1}$ and (c) $1000 \mathrm{mg} \mathrm{L}^{-1}$ SPM content, are also shown. Curves and equations correspond to respective fitting regressions. Error bars correspond to standard deviations (SD).

Figure 2. Sorption of selenium in natural SPM. (a) Se sorption kinetics $(\mathrm{N}=3)$ in freshwater (empty symbols) and seawater (filled symbols) matrices for $100 \mathrm{mg} \mathrm{L}^{-1}$ and $1000 \mathrm{mg} \mathrm{L}^{-1} \mathrm{SPM}$ content as well as (b) selenium freshwater sorption isotherms $(\mathrm{N}=2$, after $48 \mathrm{~h}$ equilibration) in $100 \mathrm{mg} \mathrm{L}^{-1}$ (triangles) and $1000 \mathrm{mg} \mathrm{L}^{-1}$ (circles) SPM content. Adsorption percentages are calculated as the difference between initial spiking concentration and $\mathrm{Se}_{\mathrm{d}}$ at each sampling time. Curves and equations correspond to respective fitting regressions. Error bars correspond to standard deviations (SD).

Figure 3. Parallel selective extractions of Te and Se. (a) Distribution of natural $\mathrm{Te}\left(\mathrm{Te}_{\mathrm{nat}}\right.$, $\mathrm{N}=3)$, (b) spiked $\mathrm{Te}\left(\mathrm{Te}_{\mathrm{ex}}, \mathrm{N}=3\right)$, (c) natural $\mathrm{Se}\left(\mathrm{Se}_{\mathrm{nat}}, \mathrm{N}=3\right)$ and (d) spiked $\mathrm{Se}\left(\mathrm{Te}_{\mathrm{ex}}, \mathrm{N}=1\right)$ in selective extractions after sorption in freshwater $(S=0)$ and seawater $(S=32)$ conditions. Targeted parallel operationally-defined solid-phase fractions were: F1 - easily exchangeable and/or carbonate fraction (acetate extraction), F2 - reducible Fe/Mn oxides (ascorbate extraction), F3 - oxidisable fraction $\left(\mathrm{H}_{2} \mathrm{O}_{2}\right.$ extraction) and $\mathrm{F} 4$ - reactive and potentially bioaccessible fraction ( $\mathrm{HCl} 1 \mathrm{M}$ extraction as $\mathrm{F} 4$ and $\mathrm{HNO}_{3} 1 \mathrm{M}$ extraction as $\left.\mathrm{F} 4 \mathrm{~N}\right)$. Percentages represent the extracted concentration in each fraction compared to total particulate concentration. Error bars correspond to standard deviations (SD). 



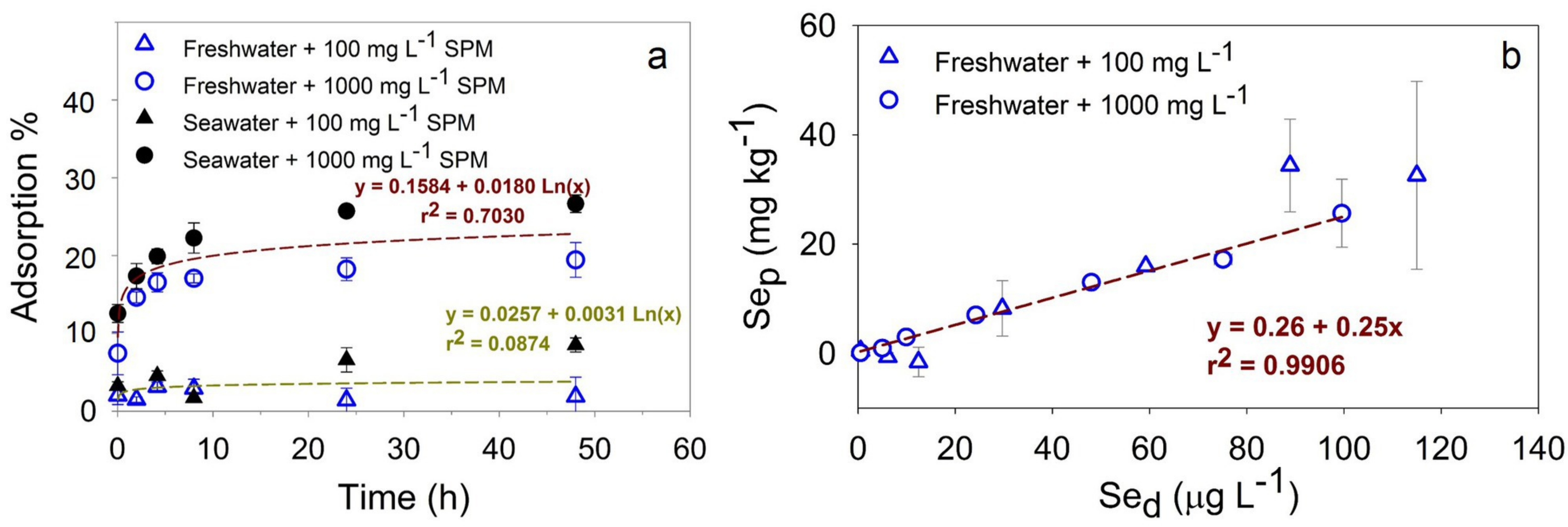


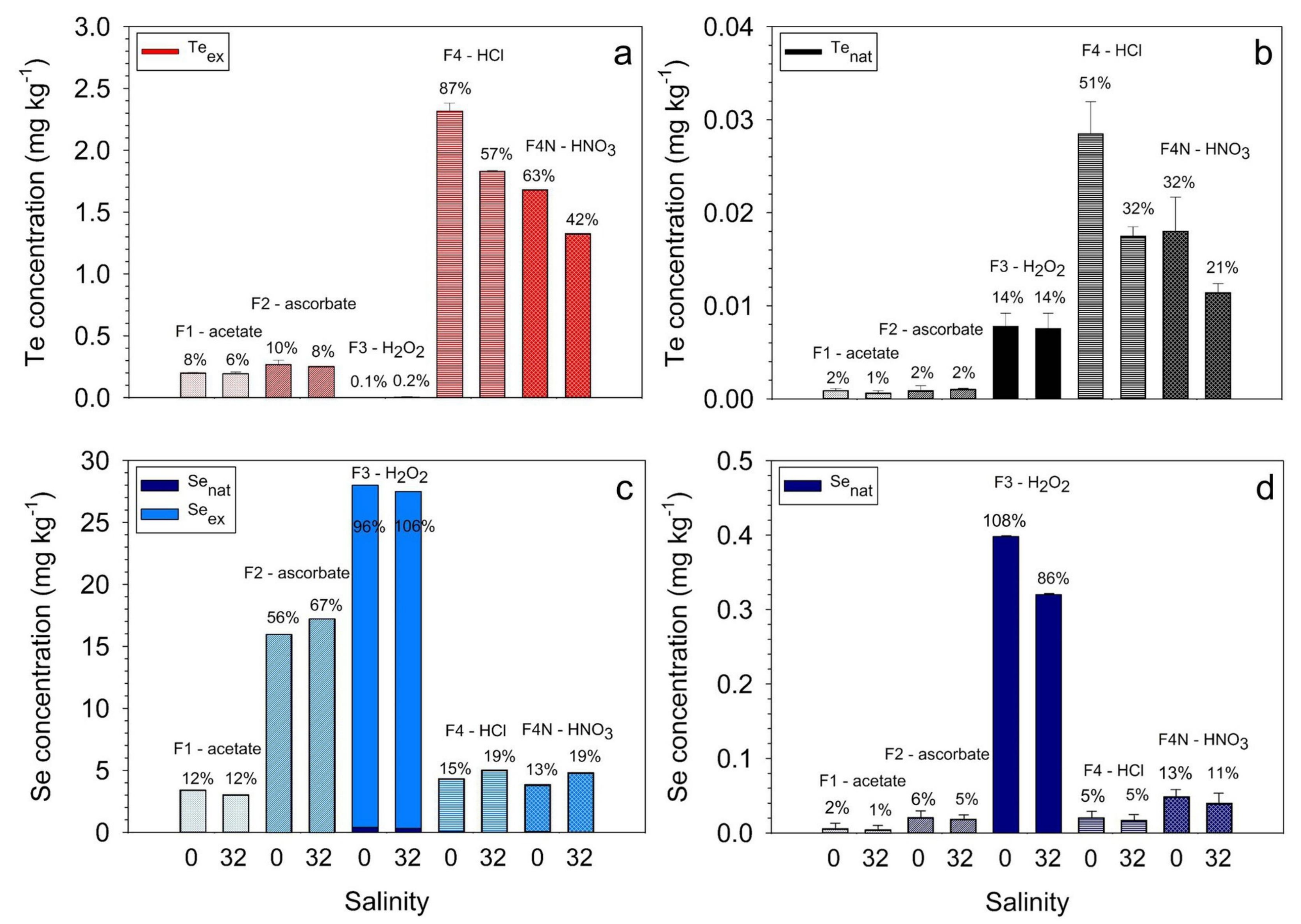


Table 1: Parallel selective extractions as described in Audry et al. (2006).

\begin{tabular}{|c|c|c|c|}
\hline Sediment fraction & $\begin{array}{c}\text { Sample } \\
\text { weight } \\
(\mathrm{mg})\end{array}$ & Reagents & Procedure \\
\hline $\begin{array}{l}\text { F1 - Acetate extraction } \\
\text { (easily exchangeable and/or } \\
\text { carbonate fraction = carbonates + } \\
\text { Mn oxyhydroxydes + sulphates + } \\
\text { organic matter) }\end{array}$ & 500 & $\begin{array}{l}10 \mathrm{ml} \text { of sodium acetate } \\
(\mathrm{NaOAc}, 1 \mathrm{M})+\mathrm{pH} \\
\text { adjustment with acetic acid } \\
(\mathrm{HOAc}, 5 \mathrm{M}) \text { during } \\
\text { extraction }\end{array}$ & $\begin{array}{l}6 \mathrm{~h} \text { shaking at } \\
25^{\circ} \mathrm{C}\end{array}$ \\
\hline $\begin{array}{l}\text { F2 - Ascorbate extraction } \\
\text { (reducible Fe/Mn oxides }=\mathrm{Mn} \\
\text { oxides and amorphous Fe oxides) }\end{array}$ & 200 & $\begin{array}{l}12.5 \mathrm{ml} \text { ascorbate solution } \\
(\mathrm{pH}=8)\end{array}$ & $\begin{array}{l}24 \text { h shaking } \\
\text { at } 25^{\circ} \mathrm{C}\end{array}$ \\
\hline $\begin{array}{l}\mathrm{F} 3-\mathrm{H}_{2} \mathrm{O}_{2} \text { extraction } \\
\text { (oxidisable fraction = organic } \\
\text { matter and labile/amorphous } \\
\text { sulphides) }\end{array}$ & 500 & $\begin{array}{l}2.5 \mathrm{ml} \mathrm{H}_{2} \mathrm{O}_{2} 30 \%(\text { at pH } 5 \\
\text { with } \mathrm{NaOH})+1.5 \mathrm{ml} \mathrm{H}_{2} \mathrm{O}_{2} \\
30 \%+2.5 \mathrm{ml} \text { ammonium } \\
\text { acetate }(1 \mathrm{M})\end{array}$ & $\begin{array}{l}2 \mathrm{~h}+3 \mathrm{~h} \text { at } \\
85^{\circ} \mathrm{C}+30 \mathrm{~min} \\
\text { shaking at } \\
25^{\circ} \mathrm{C}\end{array}$ \\
\hline $\begin{array}{l}\mathrm{F} 4 \text { - acid soluble } \mathrm{HCl} \text { extraction } \\
\text { (and complementary } \mathrm{F} 4 \mathrm{~N}-\mathrm{HNO}_{3} \\
\text { extraction) } \\
\text { (reactive and potentially } \\
\text { bioaccessible = amorphous and } \\
\text { crystalline } \mathrm{Fe} / \mathrm{Mn} \text { oxides + } \\
\text { carbonate fractions + amorphous } \\
\text { monosulphurs + phyllosilicates) }\end{array}$ & 200 & $\begin{array}{l}12.5 \mathrm{ml} \mathrm{HCl} \text { or } \mathrm{HNO}_{3} \\
(\text { Suprapur® }, 1 \mathrm{M})\end{array}$ & $\begin{array}{l}24 \mathrm{~h} \text { shaking } \\
\text { at } 25^{\circ} \mathrm{C}\end{array}$ \\
\hline
\end{tabular}

